Journal for ImmunoTherapy of Cancer

\title{
Natural killer T cell immunotherapy combined with IL-15-expressing oncolytic virotherapy and PD-1 blockade mediates pancreatic tumor regression
}

\author{
Adam Nelson (D) , ${ }^{1,2}$ Simon Gebremeskel, ${ }^{1,2}$ Brian D Lichty, ${ }^{3}$ Brent Johnston (D) ${ }^{1,2}$
}

To cite: Nelson A, Gebremeskel S, Lichty BD, et al. Natural killer T cell immunotherapy combined with IL-15-expressing oncolytic virotherapy and PD-1 blockade mediates pancreatic tumor regression. Journal for ImmunoTherapy of Cancer 2022;10:e003923. doi:10.1136/ jitc-2021-003923

- Additional supplemental material is published online only. To view, please visit the journal online (http://dx.doi.org/10. 1136/jitc-2021-003923).

Accepted 09 February 2022

A Check for updates

(c) Author(s) (or their employer(s)) 2022. Re-use permitted under CC BY-NC. No commercial re-use. See rights and permissions. Published by BMJ.

${ }^{1}$ Department of Microbiology \& Immunology, Dalhousie University, Halifax, Nova Scotia, Canada

${ }^{2}$ Beatrice Hunter Cancer Research Institute, Halifax, Nova Scotia, Canada

${ }^{3}$ Department of Pathology and Molecular Medicine, McMaster University, Hamilton, Ontario, Canada

Correspondence to

Dr Brent Johnston;

brent.johnston@dal.ca

\section{ABSTRACT}

Background Pancreatic cancer is one of the leading causes of cancer death, with a 5-year -year survival rate of less than $10 \%$. This results from late detection, high rates of metastasis, and resistance to standard chemotherapies. Furthermore, chemotherapy and radiation are associated with significant morbidity, underscoring the need for novel therapies. Recent clinical studies have shown that immunotherapies can provide durable outcomes in cancer patients, but successes in pancreatic cancer have been limited. It is likely that novel and combined therapies will be needed to achieve clinical benefits.

Methods Using experimental mouse models of pancreatic ductal adenocarcinoma, we examined natural killer T (NKT) cell activation therapy in combination with a recombinant oncolytic vesicular stomatitis virus (VSV $\triangle \mathrm{M} 51$ ) engineered to express the cytokine IL-15 (VSV-IL-15). Panc02 pancreatic ductal carcinoma cells were implanted subcutaneously or orthotopically into syngeneic C57BL/6 mice. Mice were then treated with VSV expressing green fluorescent protein (VSV-GFP) or VSV-IL-15 and/or NKT cell activation therapy via delivery of $\alpha$-GalCer-loaded DCs. We further assessed whether the addition of PD-1 blockade could increase the therapeutic benefit of our combination treatment. Three days after NKT cell activation, some groups of mice were treated with anti-PD-1 antibodies weekly for 3 weeks.

Results VSV-GFP and VSV-IL-15 mediated equal killing of human and mouse pancreatic cancer lines in vitro. In vivo, VSV-IL-15 combined with NKT cell activation therapy to enhance tumor regression and increase survival time over individual treatments, and was also superior to NKT cell therapy combined with VSV-GFP. Enhanced tumor control was associated with increased immune cell infiltration and anti-tumor effector functions (cytotoxicity and cytokine production). While ineffective as a monotherapy, the addition of blocking PD-1 antibodies to the combined protocol sustained immune cell activation and effector functions, resulting in prolonged tumor regression and complete tumor clearance in $20 \%$ of mice. Mice who cleared the initial tumor challenge exhibited reduced tumor growth uponon rechallenge, consistent with the formation of immune memory.

Conclusion TThese results demonstrate that NKT cell immunotherapy combined with oncolytic VSV-IL-15 virotherapy and PD-1 blockade enhances tumor control and presents a promising treatment strategy for targeting pancreatic cancer.

\section{BACKGROUND}

Pancreatic cancer is one of the leading causes of cancer death worldwide, with more than $90 \%$ of patients succumbing to the disease within 5 years. ${ }^{1}$ This is largely attributed to late diagnosis, a high metastasis rate, and intrinsic or acquired resistance to chemotherapy. ${ }^{2-4}$ Although improved treatments have increased survival in other cancers, survival rates in pancreatic cancer have changed little over 20 years, ${ }^{1}$ highlighting the need for effective new treatments. Immunotherapies, such as checkpoint inhibitors, can provide curative outcomes in some cancer patients. ${ }^{5}$ However, limited clinical success has been observed in pancreatic cancer, ${ }^{6} 7$ suggesting that alternate or combined immunotherapies may be required to target pancreatic cancers.

Natural killer T (NKT) cells are a specialized subset of $\mathrm{T}$ lymphocytes that play direct roles in immunosurveillance and tumor control. ${ }^{89}$ NKT cells express an invariant T cell receptor (Vo14-Jo18 in mice and the homologous V $\alpha 24-\mathrm{J} \alpha 18$ rearrangement in humans) allowing them to recognize glycolipids presented by the conserved and nonpolymorphic MHC-like molecule CD1d. ${ }^{10}$ On activation, NKT cells can release a wide array of cytokines, including interferon gamma (IFN $\gamma$ ) and tumor necrosis factor (TNF), allowing them to influence downstream immune responses. ${ }^{11}$ Preclinical and clinical studies demonstrate that activation of mouse or human NKT cells via delivery of exogenous glycolipids evokes antitumor immune responses and enhanced tumor control. $^{12}{ }^{13}$ Furthermore, infiltration of 
NKT cells or NKT-like cells (where markers used were not definitive) is associated with a good prognosis in several cancers, ${ }^{14} 15$ including pancreatic adenocarcinoma. ${ }^{16}$ Consistent with this, mice lacking NKT cells exhibit enhanced pancreatic intraepithelial neoplasia lesions when crossed with mice harboring an activating Kirsten Rat Sarcoma viral oncogene mutation. ${ }^{17}$ While NKT cell activation prior to implantation of Panc02 pancreatic adenocarcinoma cells was shown to impair tumor growth, ${ }^{18}$ the potential therapeutic benefit of NKT immunotherapy in established pancreatic cancer has not been characterized. Here we examined the therapeutic benefit of NKT cell activation alone, in combination with a recombinant oncolytic vesicular stomatitis virus (VSV) expressing interleukin-15 (IL-15), and in a triple therapy incorporating checkpoint anti-programmed cell death protein 1 (PD-1) blockade.

Oncolytic viruses selectively target cancer cells by taking advantage of dysregulated signaling pathways or metabolism. ${ }^{19}$ While oncolytic viruses can directly kill cancer cells, there is increasing evidence that they also stimulate antitumor immunity. ${ }^{20}$ VSV is a single-stranded, negativesense RNA virus with oncolytic activity that is currently being used in preclinical ${ }^{20} 22$ and clinical studies. ${ }^{23}$ Importantly, the VSV genome is amenable to modification via reverse genetics, allowing for insertion of immunomodulators. ${ }^{24}$ IL-15 is a proinflammatory cytokine essential for the survival and function of many antitumor immune cells, including NKT cells, and has been shown to increase immune targeting of cancer. ${ }^{25}{ }^{26}$ Importantly, VSV engineered to generate IL-15 induced antitumor responses that were superior to treatment with parental VSV and/ or systemic delivery of recombinant IL- $15 .{ }^{27}$ Similarly, chimeric antigen receptor NKT cells engineered to coexpress IL-15 exhibit enhanced antitumor activity, and are undergoing testing in clinical trials. ${ }^{28} 29$

Inhibitory immune checkpoint receptors, such as PD-1 and CTLA-4, are upregulated on activated leucocytes, limiting their activation and anti-tumor functions. ${ }^{30}$ Similarly, the PD-1 ligand (PD-L1) is often upregulated on cancer cells basally or in response to immunotherapies, helping tumors to evade immune targeting. ${ }^{31}$ Immune checkpoint antibodies that block inhibitory signaling receptors on immune cells have been successful in both preclinical and clinical settings. ${ }^{3233} \mathrm{PD}-1$ blockade has also been shown to preserve the antitumor functions of NKT cells. ${ }^{34}$ Therefore, blocking PD-1/PD-L1 interactions may enhance NKT cell-based combined immunotherapies.

Using subcutaneous and orthotopic mouse models of pancreatic cancer, we show that NKT cell activation in combination with VSV-IL-15 enhanced the antitumor immune response against pancreatic cancer cells, leading to increased tumor regression and overall survival time. However, all tumors relapsed over time. While anti-PD-1 therapy was ineffective on its own, supplementation of our combined immunotherapy with anti-PD-1 blockade further enhanced and prolonged the immune response, leading to extended tumor control and increased survival.

\section{METHODS}

\section{Mice}

Female C57BL/6 mice were purchased from Charles River Laboratories. J $\alpha 18^{-/-}$mice were obtained from Dr Michell Kronenberg, La Jolla Institute for Allergy \& Immunology. ${ }^{35}$ Mice were maintained in the Carleton Animal Care Facility at Dalhousie University and used at 8-12 weeks of age. Mice were group housed in temperaturecontrolled biocontainment rooms with a 12-hour light/ dark cycle and free access to food and water.

\section{Pancreatic tumor models}

Panc02 cells were harvested in the logarithmic growth phase using $0.25 \%$ trypsin-ethylenediaminetetraacetic acid (VWR). For the subcutaneous model, cells were resuspended in PBS and $2 \times 10^{6}$ cells $(100 \mu \mathrm{L}$ volume) were injected subcutaneously in the flank. Panc02 tumors were measured using electronic calipers and tumor volumes were calculated using the formula: $\mathrm{V}=\left(\mathrm{W}^{2} \times \mathrm{L}\right) / 2$. Mice were treated intratumorally on days 26,28 , and 30 with PBS, VSV-GFP or VSV-IL-15 ( $5 \times 10^{8} \mathrm{pfu} /$ mouse $)$. On day 31 , NKT cells were activated via intravenous delivery of $6 \times 10^{5}$ bone marrow derived dendritic cells (DCs) loaded with $\alpha$-GalCer (KRN7000; DiagnoCine). On days 34, 41, and 48, some mice received injections (ip. $300 \mu \mathrm{g} /$ injection) of anti-PD-1 (RMPI-14, BioXCell) or isotype control (Rat IgG2aK). Survival and tumor volume were monitored over time.

For the orthotopic model, Panc02 cells were resuspended in PBS, mixed at a 1:1 ratio with Matrigel (Corning). Following surgical exposure, $5 \times 10^{5}$ cells $(50$ $\mu \mathrm{L}$ volume) were injected into the head of the pancreas. On days 14,16 , and 18 , PBS, VSV-GFP or VSV-IL-15 $\left(5 \times 10^{8}\right.$ $\mathrm{pfu} /$ mouse) were injected intravenously. On day 19, $\alpha$-GalCer-loaded bone marrow derived DCs $\left(6 \times 10^{5}\right)$ were delivered intravenously to activate NKT cells. Survival was monitored over time.

\section{Bone marrow derived DCs}

To generate DCs, bone marrow was extracted from the femur and tibia of mice and cultured in six-well plates containing complete Roswell Park Memorial Institute (RPMI)-1640 media (10\% FBS, $50 \mu \mathrm{M}$ 2-mercaptoethanol, $2 \mathrm{mM}$ L-glutamine, $1 \times$ non-essential amino acids, $1 \mathrm{mM}$ sodium pyruvate, $100 \mu \mathrm{g} / \mathrm{mL}$ streptomycin, and 100 units/mL penicillin) supplemented with $40 \mathrm{ng} / \mathrm{mL}$ of GM-CSF and $10 \mathrm{ng} / \mathrm{mL}$ of IL-4 (PeproTech). Media was refreshed on day 3 . On day 6 , non-adherent cells were collected and replated in complete RPMI-1640 containing $20 \mathrm{ng} / \mathrm{mL}$ of GM-CSF. $\alpha$-GalCer was resuspended in a $0.05 \%$ Tween 20 PBS solution and sonicated for $20 \mathrm{~min}$ at $50^{\circ} \mathrm{C}$ before addition to the DC cultures at $0.4 \mu \mathrm{g} / \mathrm{mL}$. DCs were collected the next day for transfer into mice.

\section{Cytotoxicity and cytokine production}

Splenocytes were isolated and stained with antibodies to differentiate $\mathrm{CD} 8^{+} \mathrm{T}$ cells $\left(\mathrm{CD} 8^{+} \mathrm{TCR} \beta^{+}\right)$, NK cells $\left(\operatorname{TCR} \beta^{-}\right.$NK1. $\left.1^{+}\right)$, and NKT cells $\left(\mathrm{CD} 1 \mathrm{~d}\right.$ tetramer $\left.{ }^{+} \mathrm{TCR} \beta^{+}\right)$ 
and separated using a FACSAria III cell sorter. Sorted cells were cocultured 1:1 in complete DMEM with Oregon green labeled Panc02 cells. After 18 hours, supernatants were collected to examine IFN $\gamma$ and TNF levels via ELISA (eBioscience). Apoptosis of Oregon green-labeled Panc02 cells was examined by flow cytometry via allophycocyaninlabeled annexin $\mathrm{V}$ and 7-amino-actinomycin $\mathrm{D}$ (BioLegend) staining.

\section{T cell suppression assay}

Blood $(50 \mu \mathrm{L})$ was drawn from naïve and tumor bearing mice via submandibular venipuncture. Cells were resuspended in $200 \mu \mathrm{L}$ RPMI-1640 following red blood cell lysis, and $50 \mu \mathrm{L}$ was added to each well in a round bottomed 96-well plate. Responder splenocytes were isolated from naïve mice by mechanical dispersion through wire mesh followed by red blood cell lysis. Responder cells were labeled with $5 \mu \mathrm{M}$ Oregon green (Life Technologies) and resuspended in RPMI-1640 (supplemented with 10\% FBS, $100 \mu \mathrm{g} / \mathrm{mL}$ streptomycin, and $100 \mathrm{units} / \mathrm{mL}$ penicillin, and 1\% HEPES). Responder cells $\left(2 \times 10^{5}\right)$ were combined in wells with blood leucocytes and $\mathrm{T}$ activator anti-CD3/28 Dynabeads (Life Technologies) at a ratio of 1 bead:2 splenocytes. Cocultures were incubated at $37^{\circ} \mathrm{C}, 5 \% \mathrm{CO}_{2}$ for 72 hours. TCR $\beta^{+} \mathrm{T}$ cell proliferation was assessed by flow cytometry via Oregon green dilution.

\section{Statistics}

Data are expressed as mean \pm SEM unless otherwise stated. A non-parametric two-tailed Mann-Whitney U test was used to compare between two data groups. Comparisons between more than two data groups were made using a Kruskal-Wallis non-parametric analysis with Dunn's posttest. Tumor growth data were analyzed using area under curve, followed by a Kruskal-Wallis non-parametric analysis with Dunn's post-test. Survival data were analyzed by log-rank (Mantel-Cox) significance test. Significance was set at $\mathrm{p}<0.05$. Statistical computations were carried out using GraphPad Prism V.8.4.

\section{RESULTS \\ VSV-IL-15 infection and cytokine production in vitro and in vivo}

To test whether VSV infects and kills pancreatic cancer cells, mouse Panc02, and human Panc-1, AsPC1, and Capan-2 pancreatic ductal carcinoma lines were infected with VSV-GFP, VSV-IL-15, or UV inactivated VSV (UV-VSV). VSV-GFP and VSV-IL-15 significantly reduced the viability of mouse and human pancreatic cancer lines (online supplemental figure S1A). There were no differences in the killing activity of VSV-GFP and VSV-IL-15, indicating that incorporation of the IL-15 gene did not negatively affect the oncolytic activity of VSV. Significantly more IL-15 was released into culture supernatants following infection with VSV-IL-15 compared with UV-VSV or VSVGFP (online supplemental figure S1B). Following in vivo treatment of established subcutaneous Panc02 tumors in mice, equivalent titers of VSV-GFP and VSV-IL-15 were detected in tumor homogenates. However, VSV-IL-15 treatment significantly increased localized production of IL-15 compared with VSV-GFP (online supplemental figure S1C). In contrast, IL-15 levels in the serum were below limits of detection $(<20 \mathrm{pg} / \mathrm{mL})$. Taken together, VSV-IL-15 can infect mouse and human pancreatic cancer cells and induce localized production of IL-15.

\section{Combination of VSV and NKT cell activation induces pancreatic tumor regression}

Panc02 pancreatic ductal carcinoma cells were implanted subcutaneously $\left(2 \times 10^{6}\right.$ in $100 \mu \mathrm{L}$ of saline) into syngeneic C57BL/6 mice (figure 1A). Prophylactic NKT cell activation has been shown to limit tumor growth in this model, ${ }^{18}$ but therapeutic NKT cell activation has not been tested. Similarly, VSV has not been tested in vivo against Panc02 tumors. Tumor-bearing mice were treated with VSV-GFP or VSV-IL-15 (intratumorally (it.) $5 \times 10^{8}$ PFUs on days 26, 28, and 30) and/or NKT cell activation therapy via delivery of $\alpha$-GalCer-loaded-DCs (intravenously (iv.) $6 \times 10^{5}$ on day 31 ). Individual therapies induced modest decreases in tumor growth and increased survival time (figure 1B-C). VSV treatments combined with NKT cell activation induced superior tumor regression compared with individual therapies, with the combination of VSVIL-15 and NKT cell activation leading to the greatest tumor regression (figure 1B) and significantly longer survival time (figure 1C). To examine treatment effects on antitumor immunity, tumors and spleens were harvested on day 38 to assess immune cell accumulation (figure 1D-E). As expected, splenic NKT cells expanded following delivery of $\alpha$-GalCer-loaded DCs (figure 1D). Glycolipid treatment also increased NKT cell infiltration into the tumor (figure 1E). Oncolytic virus treatments did not expand NKT cells or cause NKT cell accumulation on their own, but VSV-IL-15 combined with NKT cell activation therapy markedly enhanced NKT cell accumulation in the tumor. None of our individual or combined treatments altered the number of NK cells, $\mathrm{CD} 8^{+} \mathrm{T}$ cells, $\mathrm{CD} 4^{+}$ $\mathrm{T}$ cells, DCs, or FoxP3 ${ }^{+}$regulatory $\mathrm{T}$ cells (Tregs) in the spleen (figure 1D). Combination therapies with VSV-GFP and NKT cell activation increased infiltration of NKT cells, $\mathrm{CD}^{+} \mathrm{T}$ cells, $\mathrm{CD} 4^{+} \mathrm{T}$ cells, and DCs into the tumors (figure 1E). Combined VSV-IL-15 and NKT cell activation therapy induced similar accumulation of $\mathrm{CD} 4^{+} \mathrm{T}$ cells and DCs in the tumor as combined therapy with VSV-GFP but enhanced NKT cell, NK cell, and CD8 ${ }^{+} \mathrm{T}$ cell accumulation (figure 1E). Overall, the combination of VSV-IL-15 and NKT cell activation effectively decreased pancreatic tumor burden and increased survival time. This was associated with increased infiltration of immune cells into the tumors.

\section{Combination of VSV and NKT cell activation induces pancreatic tumor regression in an orthotopic model}

To test our combination treatment in a more physiologically relevant microenvironment, Panc02 cells were 
A

Day 31:

$\alpha$-GalCer-loaded DC

(iv. 6x10

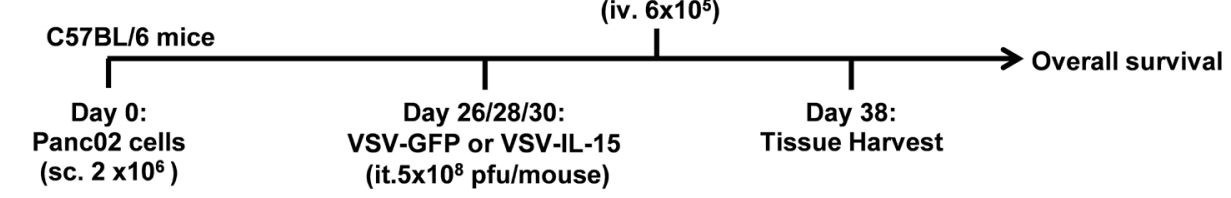

B

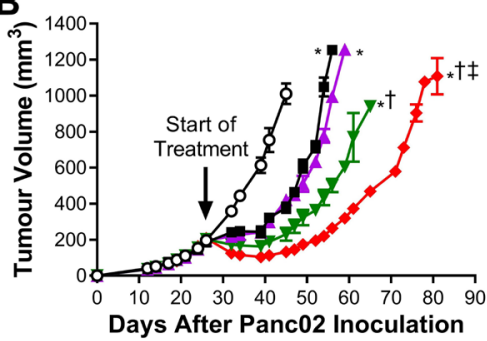

C

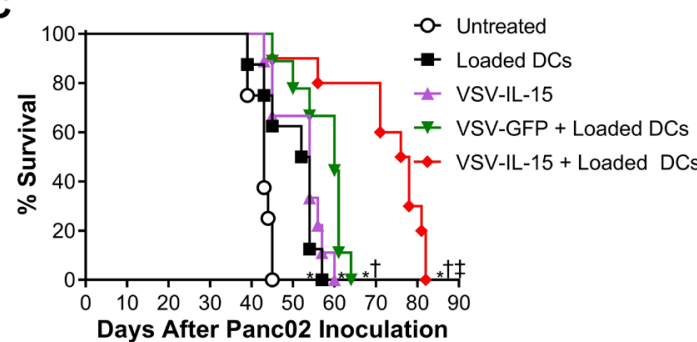

D Spleen
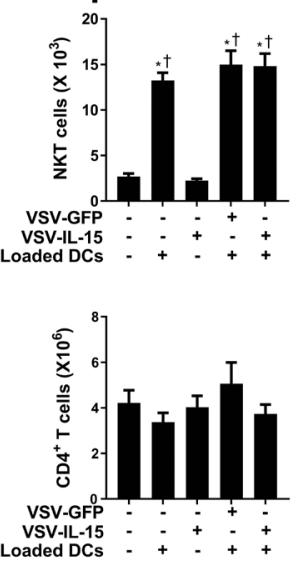

\section{E Tumor}
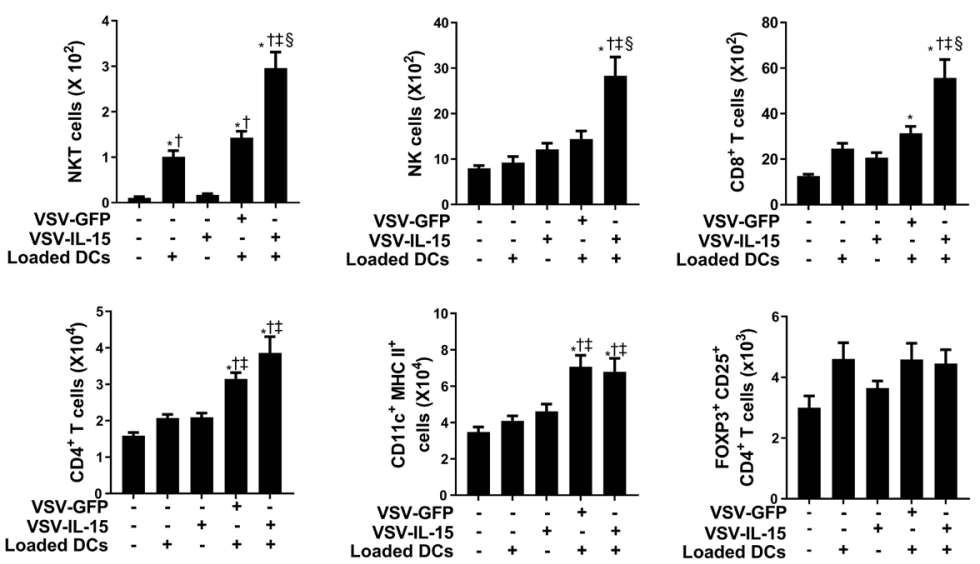

Figure 1 Combined VSV and NKT cell activation therapy induced regression of Panc02 tumors, prolonged survival, and enhanced immune cell infiltration. (A) Schematic of the subcutaneous pancreatic cancer model and treatment timeline. Subcutaneous Panc02 tumor volume (B) and survival (C) were assessed in untreated mice and mice receiving VSV-IL-15 treatments, glycolipid-loaded DCs, combined treatment with VSV-GFP plus glycolipid-loaded DCs, or combined treatment with VSV-IL-15 plus glycolipid-loaded DCs ( $n=8-12$ per group). ${ }^{*} P<0.05$ compared with untreated. ${ }^{\dagger} P<0.05$ compared with single treatments. ${ }^{\ddagger} \mathrm{P}<0.05$ compared with combined treatment with VSV-GFP plus glycolipid-loaded DCs. (D) Spleens and (E) tumors were harvested on day 38 and dispersed into single cell suspensions. Flow cytometry was used to assess accumulation of NKT cells (CD1d tetramer $\left.{ }^{+} \mathrm{TCR} \beta^{+}\right)$, NK cells $\left(\mathrm{NK} 1.1^{+} \mathrm{TCR} \beta^{-}\right), \mathrm{CD} 8^{+} \mathrm{T}$ cells $\left(\mathrm{TCR} \beta^{+} \mathrm{CD} 8 \alpha^{+}\right), \mathrm{CD} 4^{+} \mathrm{T}$ cells $\left(\mathrm{CD} 4^{+} \mathrm{TCR} \beta^{+}\right)$, T regulatory cells (Foxp3 $\left.3^{+} \mathrm{CD}_{25} \mathrm{CD}^{+}\right)$, and DCs $\left(\mathrm{MHC} \mathrm{II}^{+} \mathrm{CD}_{\left.11 \mathrm{c}^{+}\right)}(\mathrm{n}=7-12\right.$ per group). Immune cell populations in tumors were normalized per $100 \mathrm{mg}$ of tumor weight. ${ }^{*} \mathrm{P}<0.05$ compared with untreated. ${ }^{\dagger} \mathrm{P}<0.05$ compared with VSV-IL-15. ${ }^{\ddagger} \mathrm{P}<0.05$ compared with glycolipid-loaded DCs. ${ }^{\S} \mathrm{P}<0.05$ compared with combined treatment with VSV-GFP plus glycolipid-loaded DCs. DCs, dendritic cells; NKT cell, natural killer T cell; VSV, vesicular stomatitis virus. 
injected orthotopically into the pancreas of $\mathrm{C} 57 \mathrm{BL} / 6$ mice $\left(5 \times 10^{5}\right.$ in $50 \mu \mathrm{L}$ of saline and Matrigel) (figure 2A). This model is thought to better recapitulate the desmoplasia and immunosuppression seen in patients with pancreatic cancer. ${ }^{36}$ Mice were treated with VSV-GFP or VSV-IL-15 (iv. $5 \times 10^{8}$ PFUs on days 14,16 , and 18) and/or NKT cell activation therapy via delivery of $\alpha$-GalCer-loaded DCs (iv. $6 \times 10^{5}$ on day 19). Individual therapies increased survival time (figure 2B) and decreased tumor weights at day 26 (figure 2C). Combination therapy with VSV and NKT cell activation significantly increased overall survival time and tumor control, with VSV-IL-15 exhibiting better protection than VSV-GFP (figure 2B-C). Tumors and spleens were harvested on day 26 to examine immune cell populations. The patterns of immune cell expansion and infiltration were similar to the subcutaneous model. NKT cell activation therapy increased NKT cell expansion in the spleen (figure 2D), while NK cell, $\mathrm{CD} 8^{+} \mathrm{T}$ cell, $\mathrm{CD} 4^{+}$ $\mathrm{T}$ cell, DC, and Treg cell numbers were not altered by any treatments. NKT cell activation induced infiltration of NKT cells and $\mathrm{CD}^{+} \mathrm{T}$ cells into the tumor, while VSV-IL-15 on its own significantly increased $\mathrm{CD} 8^{+} \mathrm{T}$ cell infiltration (figure 2E). Combination therapy with VSVGFP and NKT cell activation increased NKT cell, CD8 ${ }^{+}$ $\mathrm{T}$ cell, $\mathrm{CD} 4^{+} \mathrm{T}$ cell, and $\mathrm{DC}$ infiltration over individual treatments, while combination therapy with VSV-L-15 caused further increases in NKT cell, NK cell, and CD8 ${ }^{+}$ $\mathrm{T}$ cell infiltration. Overall, the combination of VSV-IL-15 and NKT cell activation effectively decreased pancreatic tumor burden and increased survival, which correlated with immune cell infiltration. The orthotopic pancreatic model has a compressed timeline due to tumor-induced loss of pancreatic function, but the microenvironment appeared to have minimal impact on the pattern of therapy response in comparison with the subcutaneous model. Importantly, responses were also similar when the virus was delivered intratumorally (subcutaneous model) or intravenously (orthotopic model).

\section{Combined VSV-IL-15 and NKT cell activation increases immune cell cytotoxicity and cytokine production in subcutaneous and orthotopic models}

Since NKT cell activation, VSV, and IL-15 can all increase the function of antitumor immune cells, including NK cells, NKT cells, and CD8 ${ }^{+} \mathrm{T}$ cells, ${ }^{2026}{ }^{27}$ we examined functional immune responses in the subcutaneous and orthotopic models. To examine the effect of our treatments on the cytotoxic activity of immune cells, we sorted NK $\left(\mathrm{NK} 1.1^{+}, \mathrm{TCR} \beta^{-}\right)$, NKT $\left(\mathrm{CD} 1 \mathrm{~d}\right.$ tetramer $\left.{ }^{+}, \mathrm{TCR} \beta^{+}\right)$and $\mathrm{CD} 8^{+} \mathrm{T}$ cells $\left(\mathrm{TCR} \beta^{+}, \mathrm{CD} 8^{+}\right.$) from the spleens of untreated and treated mice and cocultured them with Oregon greenlabeled Panc02 cells. Cytotoxicity against Panc02 cells and cytokine release were examined after 18 hours (figure 3 ). NKT cells, NK cells, and CD8 ${ }^{+} \mathrm{T}$ cells from mice that had received NKT cell activation therapy exhibited increased cytotoxicity against Panc02 cells (increased 7AAD ${ }^{+} \mathrm{An}-$ nexinV ${ }^{+}$Panc02 cells), with the combination of VSV-IL-15 and NKT cell activation further increasing cytotoxicity compared with other groups (figure 3A). Treatment with VSV-IL-15 on its own did not significantly impact cytotoxicity. In addition to increased cytotoxicity, NKT cell therapy increased production of the antitumor cytokines IFN $\gamma$ (figure 3B) and TNF (figure 3C) in cocultures. Cytokine release was further enhanced using immune cells from mice that received combination therapy with NKT cell activation and VSV-IL-15. VSV-IL-15 therapy alone did not increase cytokine production in any of the cocultures. The patterns of functional responses were similar in the subcutaneous and orthotopic models at 7 days post-NKT cell activation.

\section{J $\alpha 18^{-/-}$mice lacking NKT cells have impaired tumor regression and antitumor immune responses}

Immune profiling and functional assays suggested that NKT cell activation is the critical component to initiate robust immune activation in our combination therapy. To confirm the central contribution of NKT cells, we tested our therapies in J $\alpha 18^{-/-}$mice that selectively lack NKT cells. ${ }^{35} \mathrm{~J} \alpha 18^{-/-}$mice exhibited impaired tumor control following NKT cell activation therapy and glycolipidloaded DCs were not able to synergize with VSV treatments (online supplemental figure S2A,B). Furthermore, $\mathrm{J} \alpha 18^{-/-}$mice had reduced numbers of tumor infiltrating NK and $\mathrm{CD}^{+} \mathrm{T}$ cells (online supplemental figure $\mathrm{S} 2 \mathrm{C}$ ). Mice deficient in NKT cells exhibited no increases in cytotoxicity (online supplemental figure S2D) or cytokine production (online supplemental figure S2E,F) when NK or $\mathrm{CD}^{+} \mathrm{T}$ cells were cocultured with Panc02 cells, confirming that the NKT cell activation was essential for the therapeutic benefit of the combination therapy. Although VSV treatments did not enhance immune responses in wild-type or $\mathrm{J} \alpha 18^{-/-}$mice, they did increase survival and reduce tumor weights (online supplemental figure S2A,B). Mice treated with VSV-GFP alone exhibited similar reduction in tumor weights and immune cell infiltration to mice treated with VSV-IL-15 alone (online supplemental figure S2B,C). This suggests that VSV is operating largely through oncolysis, and that IL-15 supports the NKT cell activation therapy.

\section{Combined therapy supplemented with PD-1 blockade increases survival and enhances tumor clearance}

While combined therapies induced tumor regression and increased antitumor immunity, the Panc02 tumors all relapsed and progressed over time. We hypothesized that this could be due to upregulation of immunosuppressive mechanisms that impair the immune response. The immunosuppressive checkpoint molecule PD-1 and its ligand PD-L1 are upregulated in response to proinflammatory cytokines, ${ }^{31}$ which are generated in response to our NKT cell and combination therapies. Indeed, Panc02 cells cultured in vitro with IFN $\gamma$ exhibited increased PD-L1 expression (figure 4A). Similarly, Panc02 tumor cells isolated from untreated tumorbearing mice exhibited increased PD-L1 expression, which was increased further after combination therapy 
A

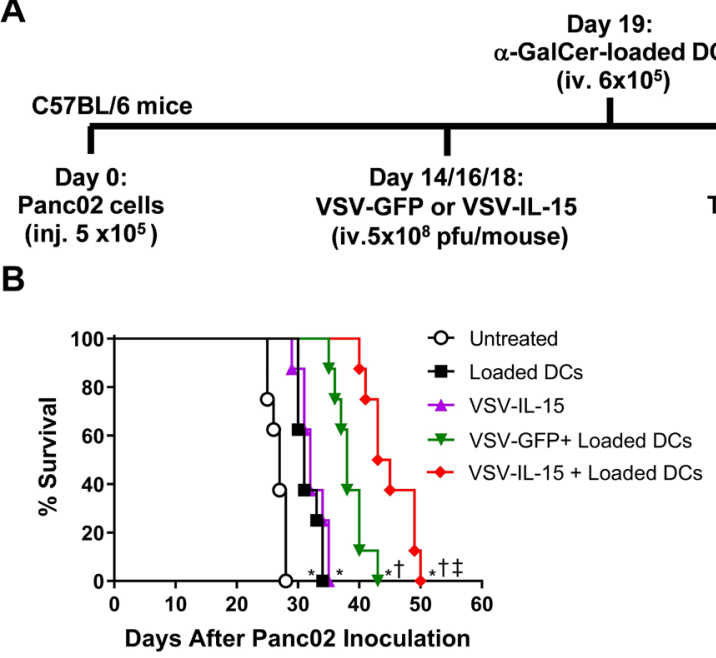

C

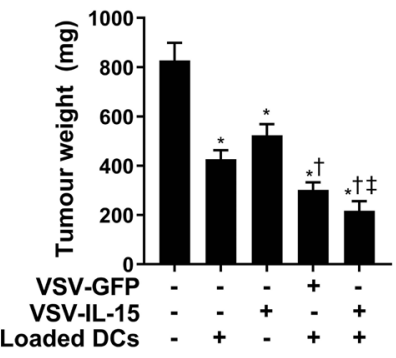

\section{Spleen}
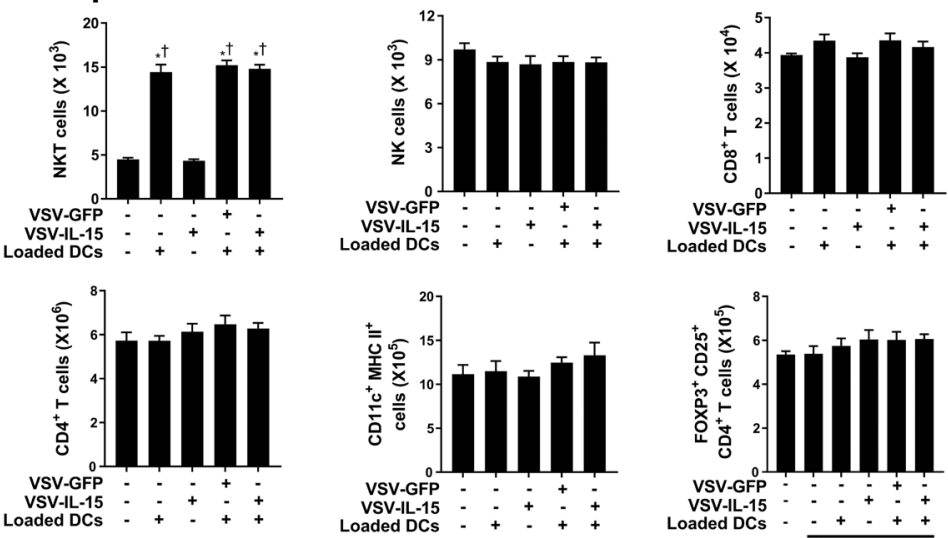

\section{E Tumor}
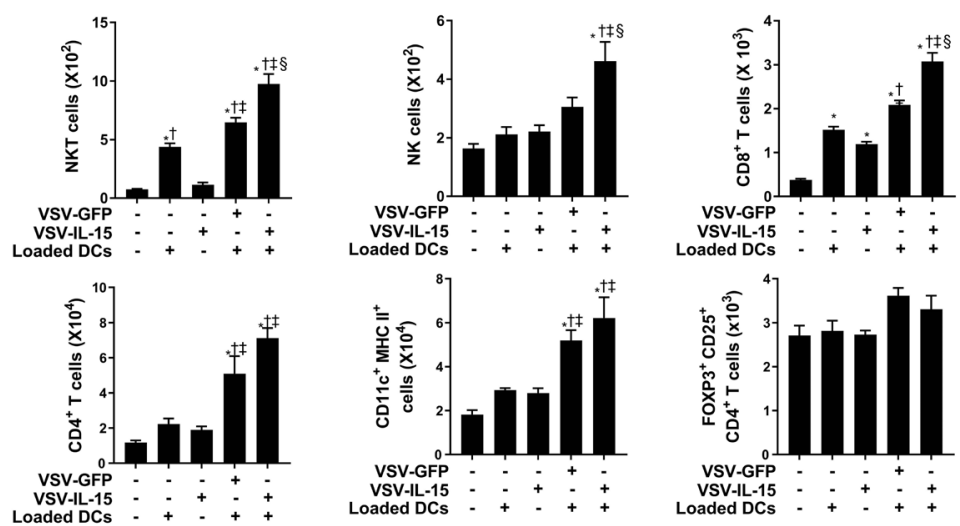

Figure 2 Combined VSV and NKT cell activation increased survival and immune cell infiltration in an orthotopic model of pancreatic cancer. (A) Schematic of the orthotopic pancreatic cancer model and treatment timeline. (B) Survival was assessed in untreated mice and mice receiving VSV-IL-15 treatments, glycolipid-loaded DCs, combined treatment with VSV-GFP plus glycolipid-loaded DCs, or combined treatment with VSV-IL-15 plus glycolipid-loaded DCs ( $\mathrm{n}=8$ per group). ${ }^{*}<0.05$ compared with untreated. ${ }^{\dagger} \mathrm{P}<0.05$ compared with single treatments. ${ }^{\ddagger} \mathrm{P}<0.05$ compared with combined treatment with VSV-GFP plus glycolipid-loaded DCs. (C) Tumors from untreated and treated mice were harvested and weighed at day 26 ( $n=6$ per group). ${ }^{\star} P<0.05$ compared with untreated. ${ }^{\dagger} P<0.05$ compared with single treatments. ${ }^{\ddagger} P<0.05$ compared with combined treatment with VSV-GFP plus glycolipid-loaded DCs. (D) Spleens and (E) tumors of mice were harvested and dispersed into single cell suspensions. Flow cytometry was used to assess NKT cells (CD1d tetramer ${ }^{+}$TCR $\left.\beta^{+}\right)$, NK cells $\left(N K 1.1^{+}\right.$TCR $\left.\beta^{-}\right)$, CD $8^{+}$T cells $\left(\mathrm{TCR} \beta^{+} \mathrm{CD} 8 \alpha^{+}\right), \mathrm{CD} 4^{+} \mathrm{T}$ cells $\left(\mathrm{CD} 4^{+} \mathrm{TCR} \beta^{+}\right)$, T regulatory cells (Foxp3 $\left.{ }^{+} \mathrm{CD} 25^{+} \mathrm{CD} 4^{+}\right)$, and $\mathrm{DCs}\left(\mathrm{MHC} \mathrm{II}{ }^{+} \mathrm{CD} 11 \mathrm{c}^{+}\right)(\mathrm{n}=6$ per group). Immune cell populations in tumors were normalized per $100 \mathrm{mg}$ of tumor weight. ${ }^{*} \mathrm{P}<0.05$ compared with untreated. ${ }^{\dagger} \mathrm{P}<0.05$ compared with VSV-IL-15. ${ }^{\ddagger} \mathrm{P}<0.05$ compared with glycolipid-loaded DCs. ${ }^{\S} \mathrm{P}<0.05$ compared with combined treatment with VSV-GFP plus glycolipid-loaded DCs. DCs, dendritic cells; NKT cell, natural killer T cell; VSV, vesicular stomatitis virus. 
NK Cells

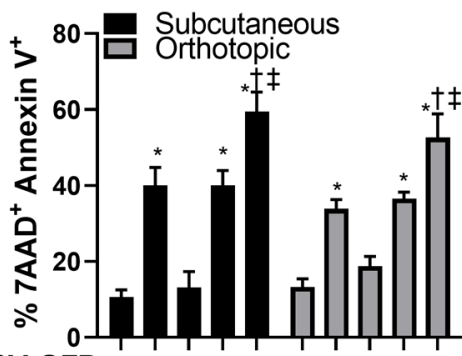

VSV-GFP - : - + - - : +

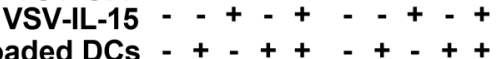

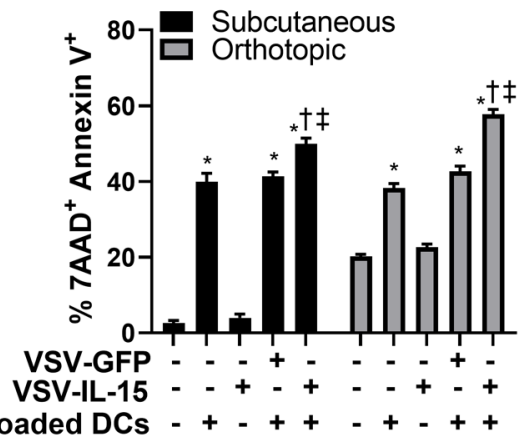

Subcutaneous Orthotopic
$\mathrm{CD}^{+} \mathrm{T}$ cells

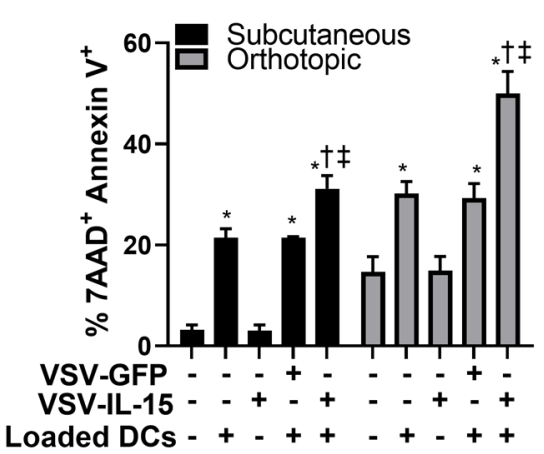

B
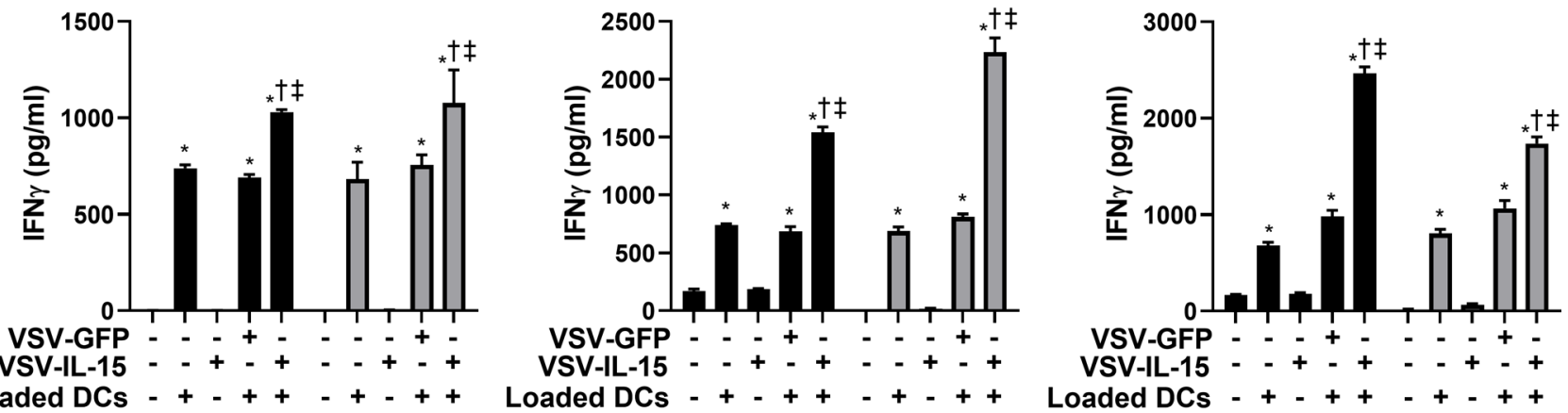

C
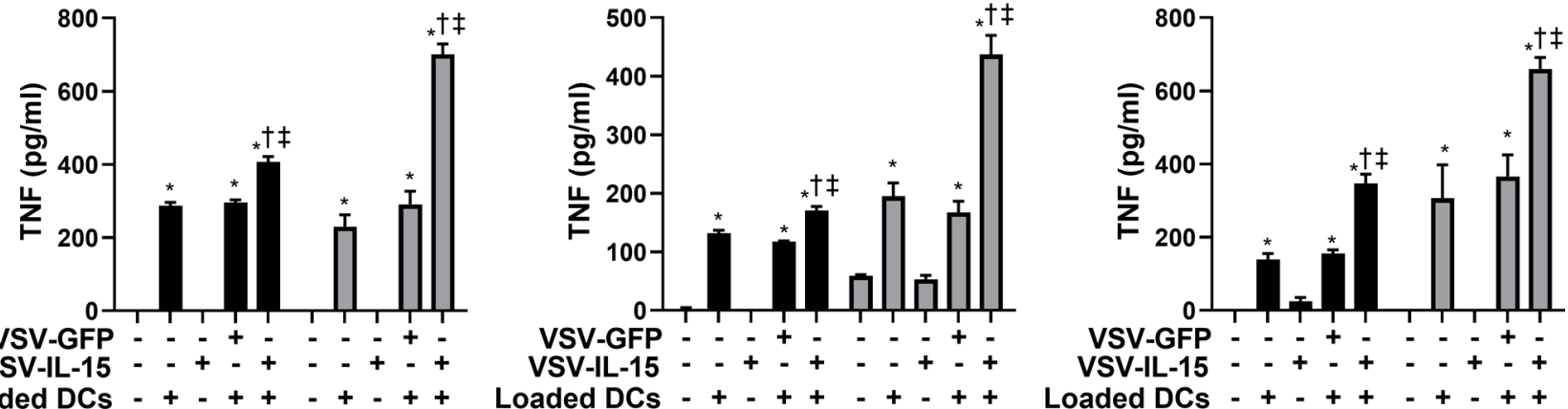

Figure 3 Combined VSV-IL-15 and NKT cell activation increased NKT cell, NK cell, and CD8 ${ }^{+}$T cell cytotoxic activity and cytokine production following in vitro restimulation with Panc02 cells. Mice with subcutaneous or orthotopic Panc02 tumors were treated as in figures $1 \mathrm{~A}$ and $2 \mathrm{~A}$, respectively. NKT cells $\left(\mathrm{CD} 1 \mathrm{~d}\right.$ tetramer $\left.{ }^{+} \mathrm{TCR} \beta^{+}\right)$, NK cells $\left(\mathrm{NK} 1.1^{+} \mathrm{TCR} \beta^{-}\right)$and $\mathrm{CD} 8^{+} \mathrm{T}$ cells $\left(\mathrm{TCR} \beta^{+} \mathrm{CD} 8 \alpha^{+}\right)$were sorted and cocultured with Oregon green labeled Panc02 cells at a 1:1 ratio. After 18 hours, Panc02 cells were stained with annexin $V$ and $7 A A D$ to assess cell killing. Culture supernatants were collected for measurement of IFN $\gamma$ and TNF by ELISA. ( $n=3-4$ per group). ${ }^{*} \mathrm{P}<0.05$ compared with untreated. ${ }^{\dagger} \mathrm{P}<0.05$ compared with glycolipid-loaded $\mathrm{DC}$ s. ${ }^{\ddagger} \mathrm{P}<0.05$ compared with combined treatment with VSV-GFP plus glycolipid-loaded DCs. DCs, dendritic cells; NKT, natural killer T cell; TNF, tumor necrosis factor; VSV, vesicular stomatitis virus.

with VSV-IL-15 and NKT cell activation (figure 4B). Concurrently, PD-1 was upregulated on an increased proportion of NKT cells, NK cells, and $\mathrm{CD}^{+} \mathrm{T}$ cells isolated from the spleen and tumor of treated mice (figure 4C-D). We therefore examined the therapeutic benefit of adding PD-1 blockade (clone RMPI-14) to our combined VSV-IL-15 and NKT cell activation regimen in our subcutaneous tumor model. Three days after NKT cell activation, mice were given anti-PD-1 (intraperitoneally (ip.) $300 \mu \mathrm{g}$ ) weekly for 3 weeks (figure $4 \mathrm{E}$ ). The addition of anti-PD-1 increased overall tumor regression and survival time, resulting in complete tumor clearance in $20 \%$ of mice (figure $4 \mathrm{~F}-\mathrm{G}$ ). Mice treated with antiPD-1 alone had no significant benefit compared with untreated mice, indicating that immune activation is required to establish benefit. Mice that survived the initial tumor challenge were rechallenged with Panc02 cells. These mice exhibited slower tumor growth compared with naïve control mice challenged with Panc02 (online supplemental figure S3A,B), indicating the presence of immune memory. Therefore, anti-PD-1 can augment our combination therapy to increase therapeutic benefit in pancreatic cancer. 
A

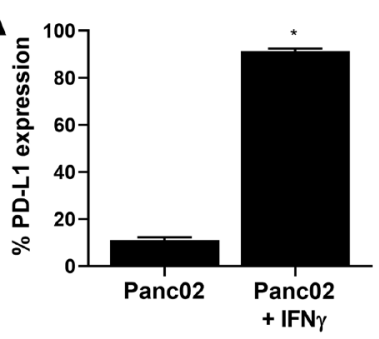

C Spleen

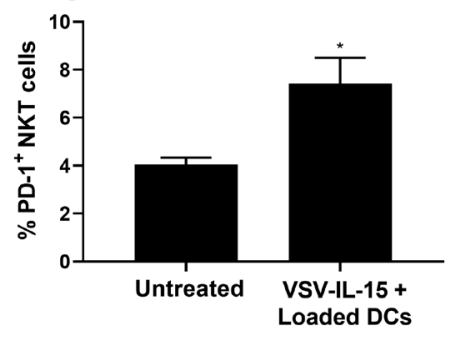

D Tumor

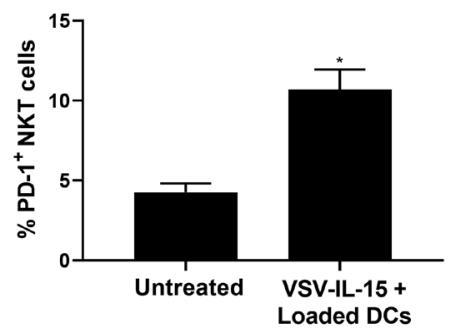

E

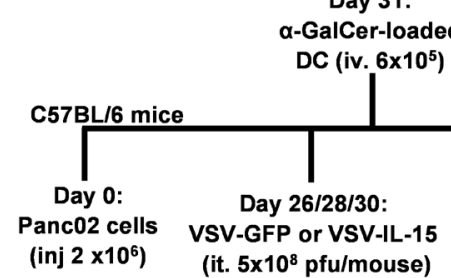

$\mathbf{F}$

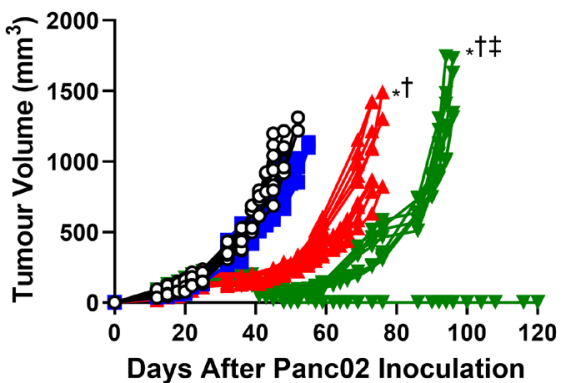

B
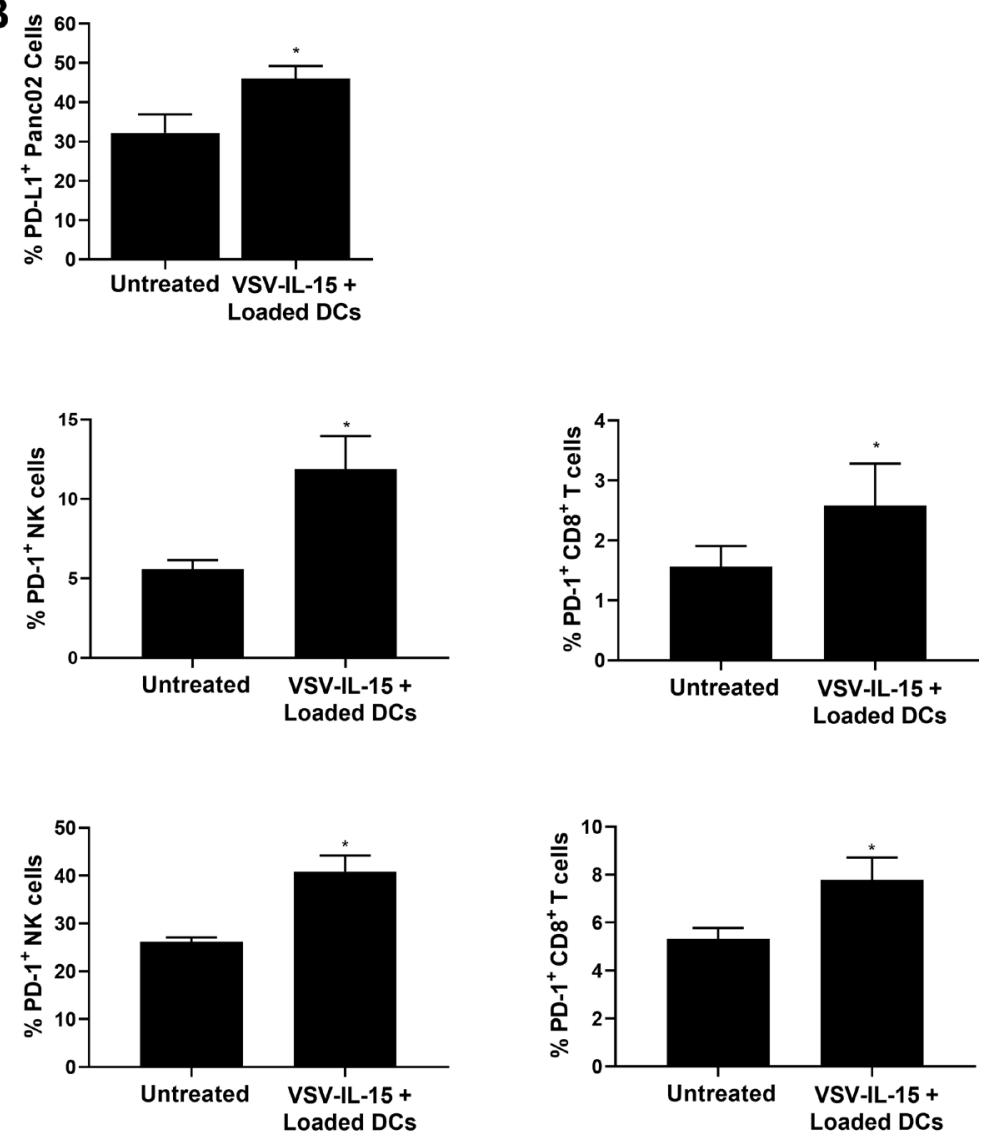

Figure 4 PD-1 blockade increased therapeutic benefit of combined VSV-IL-15 and NKT cell activation therapy against subcutaneous Panc02 tumors. (A) PD-L1 expression was measured by flow cytometry on cultured Panc02 cells supplemented with $1 \mathrm{ng} / \mathrm{mL}$ of IFN $\gamma$ for 72 hours ( $\mathrm{n}=3$ per group). ${ }^{*} \mathrm{P}<0.05$ compared with unstimulated Panc02 cells. (B) PD-L1 expression was measured on Panc02 tumor cells isolated from untreated mice and mice treated with VSV-IL-15 plus glycolipid-loaded DCs ( $n=5$ per group). * $\mathrm{P}<0.05$ compared with untreated Panc02 tumors. PD-1 expression on NKT cells $\left(C D 1 d\right.$ tetramer ${ }^{+}$TCR $\left.\beta^{+}\right)$, NK cells $\left(\mathrm{NK} 1.1^{+} \mathrm{TCR}^{-}\right)$and $\mathrm{CD}^{+} \mathrm{T}$ cells $\left(\mathrm{TCR} \beta^{+} \mathrm{CD} 8 \alpha^{+}\right)$isolated from $(\mathrm{C})$ spleens and (D) tumors of untreated mice or mice treated with VSV-IL-15 plus glycolipid-loaded DCs ( $n=5$ per group). ${ }^{*} P<0.05$ compared with untreated mice. (E) Schematic of the subcutaneous pancreatic cancer model timeline with PD-1 blockade. (F) Subcutaneous Panc02 tumor volume in individual mice and (G) overall survival and were assessed in untreated mice and mice receiving anti-PD-1 treatment alone, combined treatment with VSV-IL-15 plus glycolipid-loaded DCs, or combined treatment with VSV-IL-15, glycolipid-loaded DCs and antiPD-1 treatments ( $n=10$ per group). ${ }^{*} P<0.05$ compared with untreated. $P<0.05$ compared with anti-PD-1. ${ }^{\ddagger} P<0.05$ compared with VSV-IL-15 plus glycolipid-loaded DCs. DCs, dendritic cells; IL-15, interleukin-15; IFN $\gamma$, interferon gamma; NKT, natural killer T cell; VSV, vesicular stomatitis virus. 
PD-1 blockade enhances and maintains NK, NKT, and T cell activation induced by combination therapy

To determine the impact of anti-PD-1 treatment on immune cell populations, we harvested spleens and tumors before PD-1 therapy (day 38) or 7 days after the final anti-PD-1 treatment (day 55). At day 55, tumors in mice that only received VSV-IL-15 combined with NKT cell immunotherapy exhibited relapse and were larger than on day 38 (figure 5A). In contrast, mice that received combined VSV-IL-15 and NKT cell immunotherapy plus anti-PD-1 therapy had significantly smaller tumors (figure 5A).

While VSV-IL-15 combined with NKT cell activation increased the infiltration of NKT cells, NK cells, and $\mathrm{CD}^{+} \mathrm{T}$ cells into tumors on day 38 (figures $5 \mathrm{~B}$ and $1 \mathrm{E}$ ), by day 55 , the number of immune cells in the tumor had returned to baseline levels (figure 5B). PD-1 therapy on its own had no significant effect on immune cell infiltration. Combined treatment that incorporated anti-PD-1 therapy resulted in enhanced immune cell infiltration at day 55. Strikingly, anti-PD-1 therapy enhanced and prolonged therapy-induced immune activation as the number of NKT cells, NK cells, and $\mathrm{CD}^{+} \mathrm{T}$ cells expressing the activation marker CD69 were significantly increased compared with day 38 and day 55 groups that did not receive anti-PD-1 therapy (figure 5B). This was also observed in immune cells from the spleen (online supplemental figure S4). Anti-PD-1 therapy was associated with an increased number of PD-1 positive immune cells (figure 5B), a response consistent with enhanced immune activation. ${ }^{37}$ This could account for tumor relapse after anti-PD-1 therapy ended. Taken together, triple therapy with VSV-IL-15, NKT cell activation, and PD-1 blockade prolonged and increased immune cell activation and increased tumor regression.

\section{Combined VSV-IL-15 and NKT cell activation with PD-1 blockade increases immune cell effector function}

Due to differences in CD69 expression, we examined the effects of PD-1 blockade on cytotoxic activity and cytokine production. Immune cells from mice treated with antiPD-1 therapy alone exhibited no increase in cytotoxicity, IFN $\gamma$ release, or TNF release compared with untreated tumor-bearing mice (figure 6). While immune cells from mice treated with combined VSV-IL-15 and NKT cell therapies exhibited robust antitumor effector functions at day 38 , they were non-functional at day 55 , suggesting induction of anergy or loss of Panc02-responsive cells. In contrast, mice that received anti-PD-1 therapy in combination with VSV-IL-15 and NKT cell therapies maintained robust NKT cell, NK cell, and $\mathrm{CD} 8^{+} \mathrm{T}$ cell responses at day 55, with modest but significant increases in cytotoxicity, and cytokine production (except for TNF from NKT cells) compared with day 38. Enhanced recognition of tumor cells by NK cells was not antigen specific as NK cells from treated mice also responded when cocultured with B16-F10 melanoma cells (figure 6). In contrast, $\mathrm{CD}^{+} \mathrm{T}$ cell responses were antigen specific as there was no enhanced cytotoxicity or cytokine response in cocultures with B16-F10 cells. Therefore, the combination of VSV-IL-15, NKT cell activation, and anti-PD-1 therapies enhanced immune cell cytotoxicity against the immunizing tumor, and PD-1 therapy increased the duration of the functional antitumor immune response compared with combined treatment lacking PD-1 blockade.

\section{NKT cell activation decreases MDSC immunosuppression in subcutaneous and orthotopic models of pancreatic cancer}

In addition to checkpoint-mediated immunosuppression, the tumor and microenvironment can promote other immunosuppressive mechanisms. We did not observe an accumulation FoxP3 ${ }^{+}$regulatory $\mathrm{T}$ cells in the spleen or tumor, nor an impact of our individual or combined therapies on regulatory $\mathrm{T}$ cells (figures 1 and 2). Patients with pancreatic cancer exhibit elevated numbers of myeloidderived suppressor cells (MDSCs), ${ }^{38}$ a heterogeneous population of immature or altered granulocytic or monocytic myeloid cells that suppress immune functions. Similarly, mice with subcutaneous Panc02 tumors had elevated numbers of splenic $\mathrm{Ly}_{6} \mathrm{G}^{+} \mathrm{CD} 11 \mathrm{~b}^{+}$cells compared with naïve mice lacking tumors (figure 7A). While NKT cell activation on its own did not significantly increase the number of $\mathrm{Ly}_{6 \mathrm{G}^{+}} \mathrm{CD} 11 \mathrm{~b}^{+}$cells in the spleen (figure $7 \mathrm{~A}$ ) or tumor (figure 7B), treatment with VSV increased these cells in both the subcutaneous and orthotopic Panc02 models. In the tumor, this was further enhanced by combined VSV and NKT cell activation therapies, with VSV-IL-15 inducing accumulation of more $\mathrm{Ly}_{6 \mathrm{G}}^{+} \mathrm{CD} 11 \mathrm{~b}^{+}$ cells than VSV-GFP (figure 7B). Similar results were observed in the orthotopic Panc02 model (online supplemental figure S5A,B). Our lab has previously shown that NKT cell activation decreases MDSC-mediated immunosuppression in a $4 \mathrm{~T} 1$ breast cancer model. ${ }^{12}$ Blood cells from naïve, untreated tumor-bearing mice, and treated tumor-bearing mice were tested for their ability to suppress proliferation of Oregon green-labeled naïve $\mathrm{T}$ cells cocultured with anti-CD3/CD28-coated stimulator beads. Blood $\mathrm{Ly}_{6} \mathrm{G}^{+} \mathrm{CD}_{11} \mathrm{~b}^{+}$cells from untreated tumorbearing mice exerted significant immunosuppression compared with cells from naive mice (figure 7C). Blood leucocytes from mice that had received NKT cell activation therapy exhibited a partial reduction in immunosuppressive activity (figure 7C), resulting in increased $\mathrm{T}$ cell proliferation. Although VSV-IL-15 treatment increased the frequency of $\mathrm{Ly}_{6 \mathrm{G}} \mathrm{C}^{+} \mathrm{CD} 11 \mathrm{~b}^{+}$cells, VSV-IL-15 treatment on its own did not further enhance tumor-induced immunosuppression (figure 7C). Treatment with VSV did not impair the NKT cell-mediated reversal of suppressive activity. Similar results were observed in the orthotopic Panc02 model (online supplemental figure S5). The inhibition of suppression was NKT cell dependent as there was no rescue of $\mathrm{T}$ cell proliferation using blood leucocytes from NKT cell-deficient J $\alpha 18^{-/-}$mice (figure 7C).

Treatment with PD-1 checkpoint therapy did not reduce the VSV-induced accumulation of $\mathrm{Ly}_{6} \mathrm{G}^{+} \mathrm{CD} 11 \mathrm{~b}^{+}$cells in the spleen (figure 7D). In the tumor, $\mathrm{Ly}_{6 \mathrm{G}^{+}} \mathrm{CD}_{11 b^{+}}$cells 


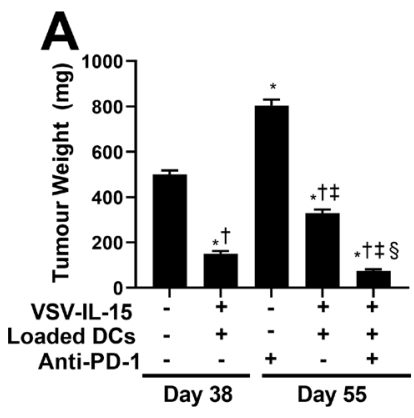

\section{B Tumor}
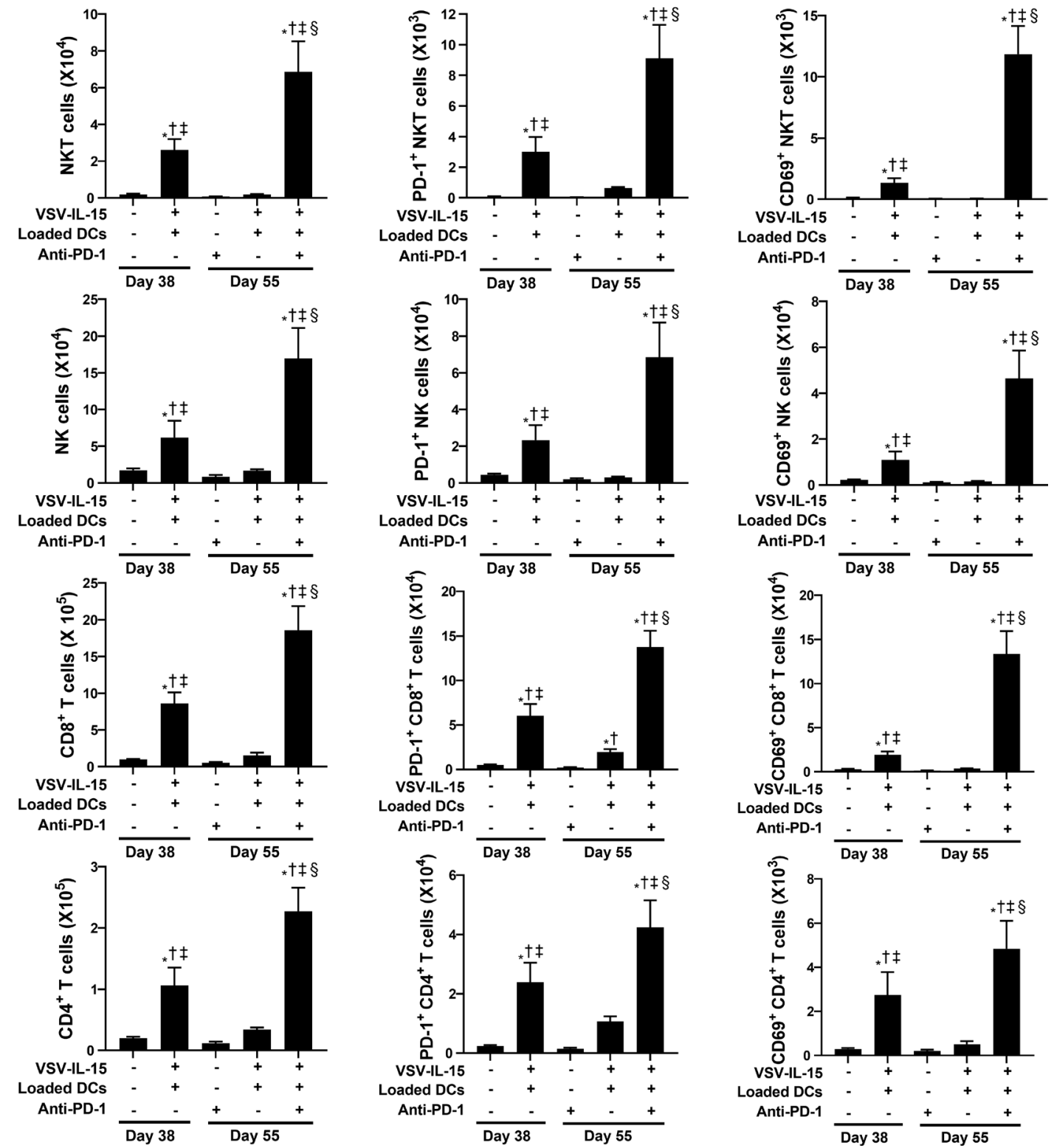

Figure 5 PD-1 blockade increased activation of tumor infiltrating lymphocytes following combined VSV-IL-15 and NKT cell activation therapies. Subcutaneous Panc02 tumors were induced and treated as in figure 4E. (A) Tumors of untreated and treated mice were harvested and weighed at day 38 or 55 ( $n=3-6$ per group). (B) Tumors were dispersed into single cell suspensions, and flow cytometry was used to assess NKT cell (CD1d tetramer ${ }^{+}$TCR $\beta^{+}$), NK cell $\left(\mathrm{NK} 1.1^{+} \mathrm{TCR} \beta^{-}\right), \mathrm{CD} 8^{+}$T cell $\left(\mathrm{TCR} \beta^{+} \mathrm{CD} 8 \alpha^{+}\right)$, and $\mathrm{CD} 4^{+} \mathrm{T}$ cell $\left(\mathrm{TCR} \beta^{+} \mathrm{CD} 4^{+}\right)$infiltration into tumors. Expression of $\mathrm{CD} 69$ and $\mathrm{PD}-1$ were examined $(\mathrm{n}=3-6$ per group). Immune cell populations in tumors were normalized per $100 \mathrm{mg}$ of tumor weight. Cell populations were also examined in the spleen (see online supplemental figure S5). ${ }^{*} P<0.05$ compared with untreated. $+P<0.05$ compared with anti-PD-1. ${ }^{\ddagger} P<0.05$ compared with VSV-IL-15 plus glycolipid-loaded DCs (day 38 ). ${ }^{\circledR} \mathrm{P}<0.05$ compared with VSV-IL-15 plus glycolipid-loaded DCs (day 55). DCs, dendritic cells; IL-5, interleukin-15; NKT, natural killer T cell; VSV, vesicular stomatitis virus. 
NKT cells
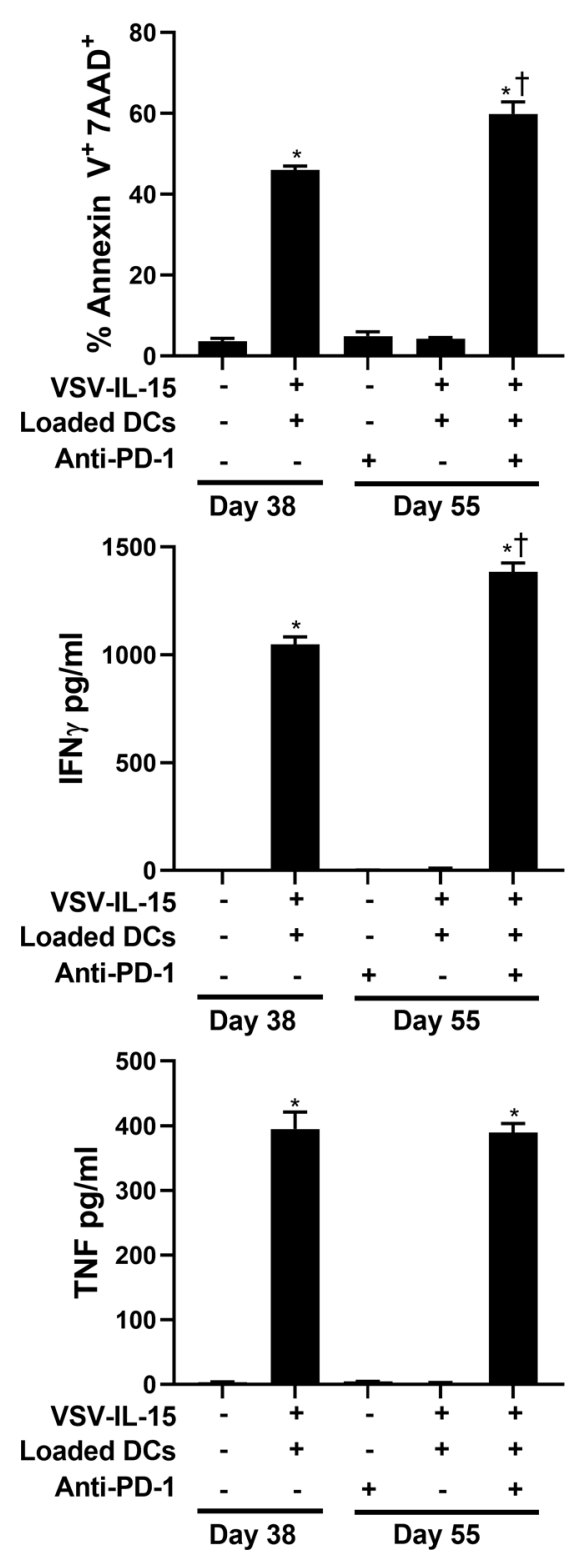

NK cells
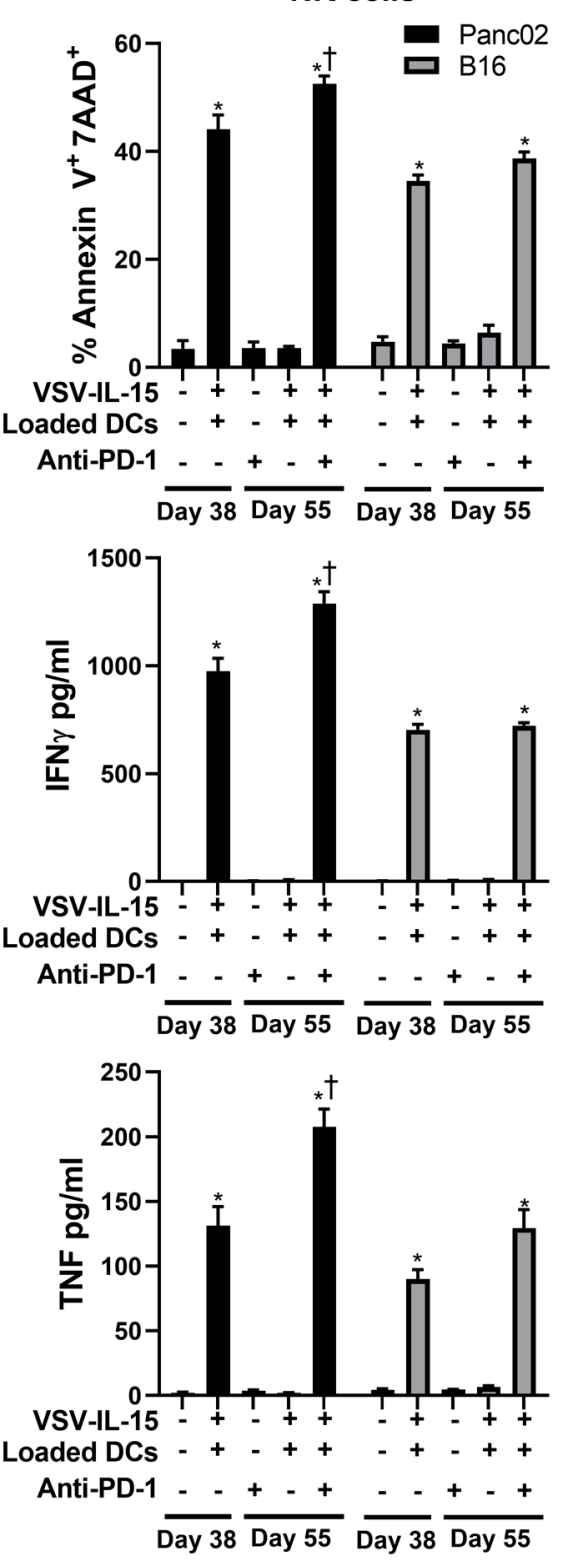

\section{$\mathrm{CD}^{+} \mathrm{T}$ cells}

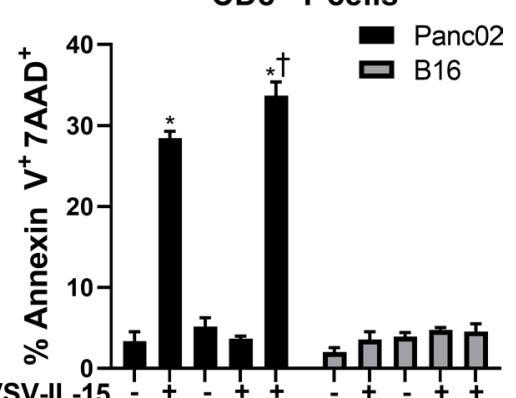

VSV-IL-15 $-+++2+++$

Loaded DCs - + - + + + + -+

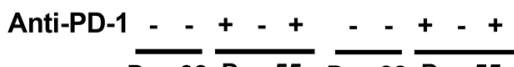

$\overline{\text { Day } 38} \overline{\text { Day } 55} \overline{\text { Day } 38} \overline{\text { Day } 55}$
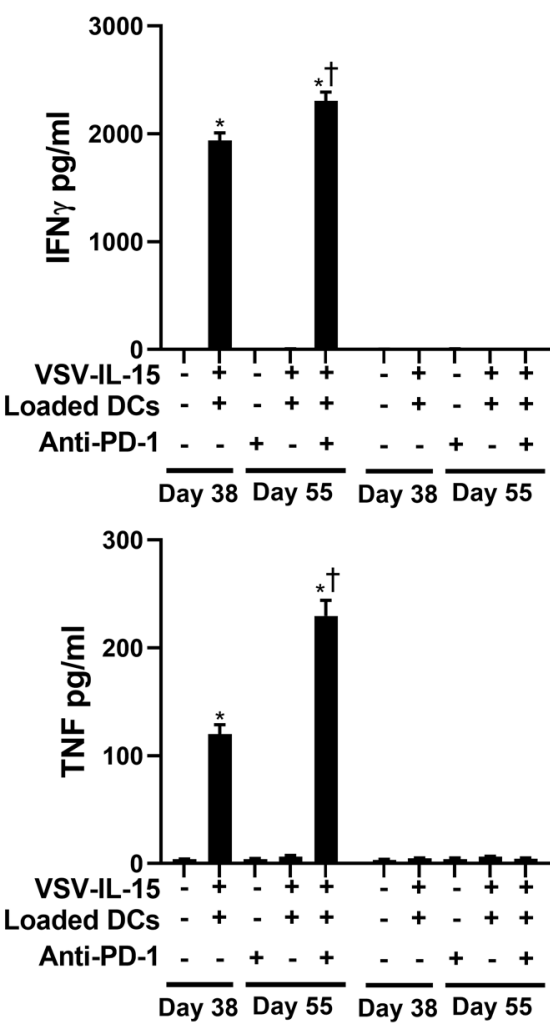

Figure 6 Combined VSV-IL-15, NKT cell activation, and PD-1 blockade increased NK, NKT and CD8 ${ }^{+}$T cell cytotoxicity and cytokine production following in vitro restimulation with Panc02 cells. Mice with subcutaneous Panc02 tumors were treated as in figure 4E. NKT cells $\left(C D 1 d\right.$ tetramer $\left.{ }^{+} T C R \beta^{+}\right)$, NK cells $\left(N K 1.1^{+} \mathrm{TCR} \beta^{-}\right)$and $\mathrm{CD} 8^{+} \mathrm{T}$ cells $\left(\mathrm{TCR} \beta^{+} \mathrm{CD} 8 \alpha^{+}\right)$were sorted and cocultured with Oregon green labeled Panc02 cell or B16-F10 melanoma cells at a 1:1 ratio. After 18 hours, Panc02 and B16-F10 cells were stained with annexin $\mathrm{V}$ and 7-AAD to assess cytotoxicity. Culture supernatants were collected for measurement of IFN $\gamma$ and TNF by ELISA ( $n=4$ per group). ${ }^{*} P<0.05$ compared with untreated. $\dagger P<0.05$ compared with VSV-GFP plus glycolipid-loaded DCs. DCs, dendritic cells; IFN $\gamma$, interferon gamma; NKT, natural killer T cell; TNF, tumor necrosis factor; VSV, vesicular stomatitis virus.

were increased following anti-PD-1 therapy (figure 7E). As with the immune function assays, the benefit of NKT cell activation therapy against immunosuppression was lost at day 55 (figure 7F). However, the addition of antiPD-1 therapy extended the ability of combined NKT cell activation and VSV-IL-15 therapy to impede immunosuppressive activity (figure 7F). Taken together, NKT cell activation can reduce immunosuppression in pancreatic cancer models and anti-PD-1 therapy can prolong this benefit.

\section{DISCUSSION}

Current treatments for pancreatic cancer are largely ineffective and lead to many adverse events, ${ }^{39}$ highlighting the need for effective new treatments. Here we tested NKT cell activation in combination with VSV expressing IL-15 as a potential treatment for pancreatic cancer. Combination treatment led to immune cell infiltration and increased cytotoxic lymphocyte function, resulting in enhanced tumor regression and overall survival time in subcutaneous and orthotopic transplantable tumor 
A

Splenic Granulocytes

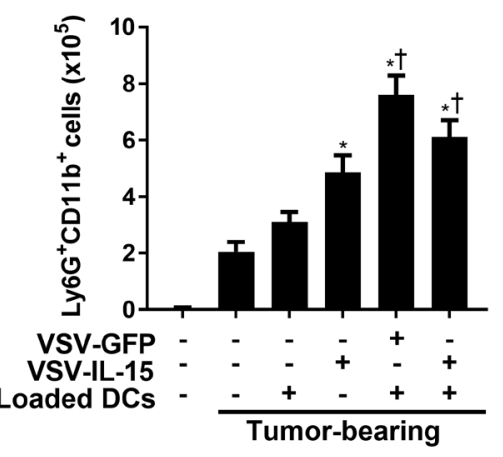

B

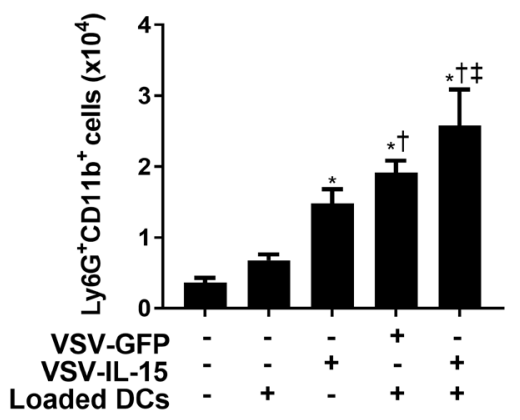

C

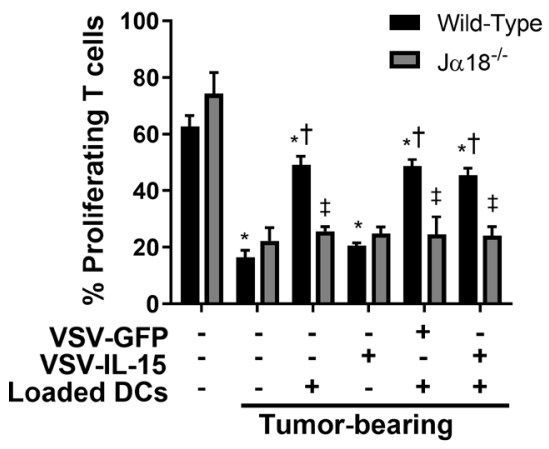

D Splenic Granulocytes

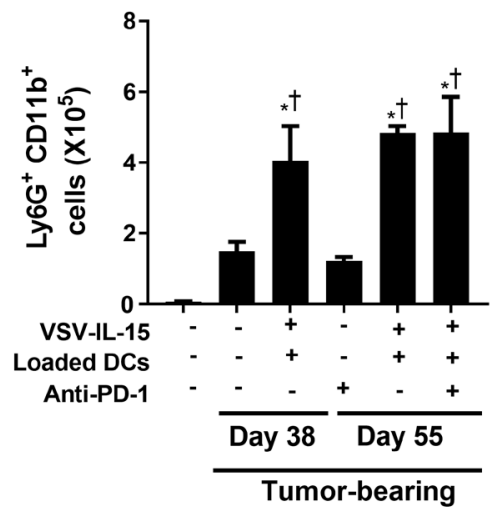

E

Tumour Granulocytes

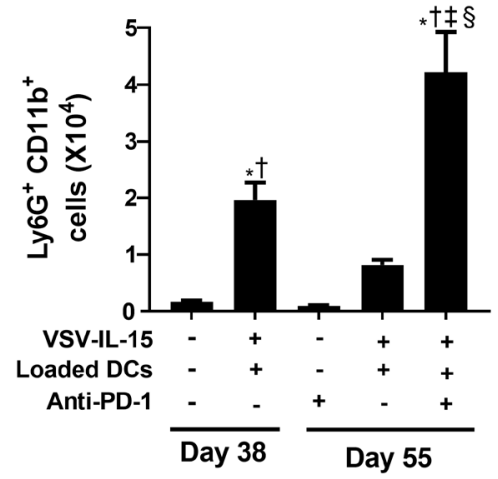

$\mathbf{F}$

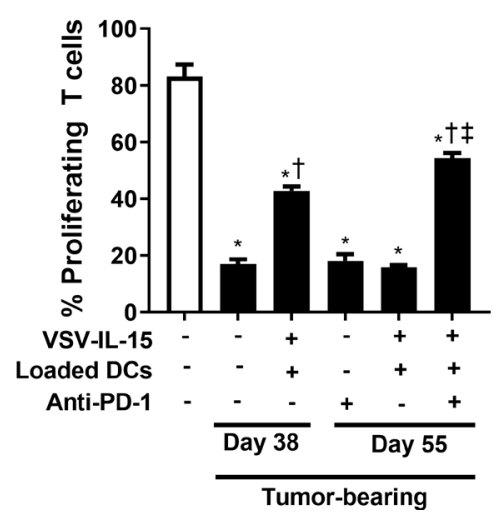

Figure 7 VSV induced granulocyte accumulation, while NKT cell activation decreased MDSC-mediated immunosuppression in pancreatic cancer. Subcutaneous Panc02 tumors were induced and treated with VSV and glycolipid-loaded DCs as in figure 1A. (A) Spleens and (B) tumors were harvested and dispersed into single cell suspensions. Flow cytometry was used to assess accumulation of granulocytic ( $\left(\mathrm{Ly}_{6} \mathrm{G}^{+} \mathrm{CD} 11 \mathrm{~b}^{+}\right)$cells $(\mathrm{n}=5-9$ per group). Granulocytic cells in tumors were normalized per $100 \mathrm{mg}$ of tumor weight. ${ }^{*} \mathrm{p}<0.05$ compared with untreated. ${ }^{\dagger} \mathrm{P}<0.05$ compared with glycolipid-loaded $\mathrm{DCs} .{ }^{\ddagger} \mathrm{P}<0.05$ compared with VSV-IL-15. (C) Naïve splenocytes from wild-type or J $\alpha 18^{-/-}$mice were stained with Oregon green and cultured with CD3/ CD28 beads. Blood granulocytes from untreated and treated mice were added to the cocultures for 72 hours. T cells $\left(\right.$ TCR $\left.\beta^{+}\right)$ were stained and examined for proliferation via Oregon green dilution ( $n=4-7$ per group). ${ }^{*} P<0.05$ compared with naîve. ${ }^{\dagger} P<0.05$ compared with untreated. ${ }^{\ddagger} \mathrm{P}<0.05$ compared with wild-type. Subcutaneous Panc02 tumors were induced and treated with VSV, glycolipid-loaded DCs, and PD-1 blockade as in figure 4E. (D) Spleens and (E) tumors were harvested and dispersed into single cell suspensions. Flow cytometry was used to assess accumulation of granulocytic $\left(\right.$ Ly6G $\left.{ }^{+} \mathrm{CD}_{11} \mathrm{~b}^{+}\right)$cells $(n=3-6$ per group). Granulocytic cells in tumors were normalized per $100 \mathrm{mg}$ of tumor weight. ${ }^{*} \mathrm{P}<0.05$ compared with untreated. $\dagger \mathrm{P}<0.05$ compared with anti-PD-1. ${ }^{\ddagger} \mathrm{P}<0.05$ compared with VSV-IL-15 plus glycolipid-loaded DCs (day 38 ). ${ }^{\S} \mathrm{P}<0.05$ compared with VSVIL-15 plus glycolipid-loaded DCs (day 55). (F) Splenocytes from naive mice were stained with Oregon green and cultured with CD3/CD28 beads. Blood leucocytes from untreated and treated mice were added to the coculture for 72 hours. T cells (TCR $\left.\beta^{+}\right)$ were stained and examined for proliferation ( $n=3-5$ per group). ${ }^{*} P<0.05$ compared with naiive. ${ }^{\dagger} P<0.05$ compared with untreated. ${ }^{\ddagger} \mathrm{P}<0.05$ compared with VSV-IL-15 plus glycolipid-loaded DCs (day 38). DCs, dendritic cells; IL-15, interleukin-15; MDSCs, myeloid-derived suppressor cells; VSV, vesicular stomatitis virus. 
models. NK, NKT, and $\mathrm{CD}^{+} \mathrm{T}$ cells from treated mice exhibited increased cytotoxicity and proinflammatory cytokine production in coculture with Panc02 cells. This increased cytotoxicity and cytokine production was dependent on NKT cell activation, as VSV-IL-15 therapy alone did not increase cytotoxicity or cytokine production. Furthermore, the increased cytotoxicity and cytokine production were lost in NKT cell deficient mice, reinforcing a central role for NKT cells in coordinating tumor control. The therapeutic benefit of combined VSV-IL-15 plus NKT cell activation could be augmented and prolonged by adding anti-PD-1 checkpoint therapy to the treatment regimen. The addition of PD-1 blockade increased and maintained NK, NKT and $\mathrm{CD} 8^{+} \mathrm{T}$ cell activation and effector function (cytotoxicity and cytokine production), resulting in further tumor regression and complete tumor clearance in $20 \%$ of mice.

The subcutaneous and orthotopic pancreatic cancer models exhibited similar responses to treatment, with similar changes in immune cell populations, cytotoxicity, and cytokine production. This suggests that both local and systemic oncolytic virus delivery work to enhance NKT cell immunotherapy. The similarity in the results also demonstrates that the subcutaneous model is a relevant model for testing future therapeutic strategies for pancreatic cancer.

Therapy-induced $\mathrm{CD}^{+} \mathrm{T}$ cell cytotoxicity was dependent on Panc02 tumor-specific antigens as subsequent immune cell cocultures with B16-F10 melanoma cells exhibited no increase in cytotoxicity or cytokine production. NK cell priming however was not tumor specific as these cells also exhibited heightened cytotoxicity against B16-F10 cells. We could not obtain sufficient NKT cells from sorting to test their response against both Panc02 and B16-F10 cells. However, since NKT cells can recognize multiple glycolipid ligands presented via $\mathrm{CD} 1 \mathrm{~d}^{10}$ and NKT cells can target B16-F10, ${ }^{34}$ it would be expected that NKT cell activity would not be tumor specific.

While VSV-IL-15 induced tumor regression as a monotherapy, it did not significantly increase NKT, NK or CD8 ${ }^{+}$ $\mathrm{T}$ cell cytotoxic activity or cytokine production (figure 3 ), suggesting that tumor regression with this treatment was largely due to the oncolytic activity of VSV and not increased IL-15 signaling. In previous studies, IL-15 production from VSV-IL-15 enhanced antitumor immune responses and clearance of CT26 tumors, ${ }^{27}$ suggesting that increased IL-15 can modulate tumor immunity in some models. The mechanisms underlying differences between the responses in these models are unclear as the same viral construct was used. It could be related to relatively poor baseline immune activity and immune cell infiltration in the Panc02 model. In this model, NKT cell activation increased immune cell infiltration, facilitating an immune function benefit when therapy was combined with VSV-IL-15 vs VSV-GFP. The lack of baseline immune activity in Panc02 tumors could also explain the ineffectiveness of anti-PD-1 monotherapy (figure $4 \mathrm{~F}-\mathrm{G}$ ). These results agree with findings that anti-PD-1 therapy is ineffective in cold tumors, including pancreatic cancer. ${ }^{40}$ Anti-PD-1 therapy has realized more success in cold tumors when combined with therapies that turn these tumors hot by increasing immune cell infiltration. ${ }^{41} \mathrm{VSV}-$ IL-15 in combination with NKT cell activation increased immune cell infiltration, leading to PD-1 therapy being more effective then when used alone. Furthermore, NKT cell activation can overcome $\mathrm{CD} 8^{+} \mathrm{T}$ cell exhaustion, increasing efficacy of anti-PD-1 in checkpoint inhibitor resistant tumors. ${ }^{42}$ In contrast to our findings in the Panc02 model, VSV increased immune cell infiltration in other tumor models, alone and in combination with checkpoint therapies. ${ }^{202}$

Previous studies have shown that NKT cell activation by $\alpha$-GalCer induces $\mathrm{CD}^{+}$and $\mathrm{CD} 8^{+}$memory $\mathrm{T}$ cell formation. $^{43}$ Therefore, we expect that NKT cell activation drove memory responses in our cancer model. Interestingly, mice that did not clear Panc02 tumors lost their antitumor immune response by day 55 . As PD-1 therapy was able to maintain antitumor immune responses, it suggests that the loss in activity is primarily through the action of immunosuppressive mechanisms rather than loss of specificity. This is supported by the ability of mice that survived the initial Panc02 tumor challenge following triple therapy to impede tumor growth following tumor rechallenge, demonstrating that immune memory was maintained.

Previously our lab has shown that NKT cell activation reduces MDSC-mediated immune suppression in a $4 \mathrm{~T} 1$ breast cancer model. ${ }^{12}$ Here we show that NKT cell activation also reduces immune suppression in pancreatic cancer models. This is important since immunosuppression is a major factor in pancreatic cancer disease progression. ${ }^{38}$ In the Panc02 model, granulocytic MDSCs accumulate in the bone marrow, spleen, and tumor, driving tumor growth via the release of immunosuppressive and protumor cytokines. ${ }^{38} 44$ One mechanism by which NKT cells may target MDSC activity is by inhibiting their nitric oxide production. ${ }^{45}$ While combining NKT cell therapy with VSV did not increase the ability of NKT cells to suppress MDSCs, combination therapy with anti-PD-1 enhanced and prolonged protective effects. As activated NKT cells undergo anergy by upregulating PD-1, ${ }^{34}$ blocking the PD-1/PD-L1 axis can maintain NKT antitumor function, ${ }^{34}$ suggesting anti-PD-1-therapy increases the ability of NKT cells to suppress MDSCs. The exact mechanism underlying how NKT cells inhibit MDSC-mediated immunosuppression in cancer needs to be further elucidated. Previous studies have implicated CD1d, CD40, and NKG2D interactions in NKT cellmediated regulation of MDSCs. ${ }^{45}$

Overall, triple therapy with VSV-IL-15, NKT cell activation, and anti-PD-1 presents a novel approach for treating pancreatic cancer. Gemcitabine and FOLFIRINOX, the current standard of care for pancreatic cancer, are largely ineffective long term and come with severe adverse effects. ${ }^{39}$ VSV infection is associated with mild flu-like symptoms, ${ }^{46}$ while NKT cell activation in patients 
is associated with low grade adverse effects. ${ }^{47}$ Anti-PD-1 therapies are mostly associated with grade 1-2 adverse effects, with severe adverse effects occurring in 10\%-20\% of patients. ${ }^{48}$ Even though combined therapy was only able to clear tumors in $20 \%$ of mice, this is similar to the initial outcomes in melanoma patients treated with checkpoint blockade. ${ }^{49}$ Additionally, combined therapy as a neoadjuvant treatment could enhance tumor regression in patients to make them better candidates for surgery, an important consideration since $80 \%$ of patients with pancreatic cancer do not meet eligibility guidelines based on tumor size and invasiveness. ${ }^{50}$ Therefore, our combined immunotherapy approaches could provide a safe and effective alternative to the current standards of care.

Contributors Conceptualization: $\mathrm{AN}$ and $\mathrm{BJ}$; methodology: AN and SG; formal analysis: $\mathrm{AN}$; investigation: $\mathrm{AN}$; resources: $\mathrm{AN}, \mathrm{BDL}$ and $\mathrm{BJ}$; writing - original draft: $A N$; writing - review and editing; all authors; visualization: $A N$ and $B J$; supervision: $\mathrm{BJ}$; funding acquisition: $\mathrm{AN}$ and $\mathrm{BJ}$; guarantor: $\mathrm{BJ}$.

Funding This study was supported by an operating grant from the Canadian Institutes of Health Research (PJT-153285). AN received a studentship from the Beatrice Hunter Cancer Research Institute with funding from The Terry Fox Research Institute, CIBC, and Craig's Cause Pancreatic Cancer Society. SG received a studentship from the Canadian Institutes of Health Research.

\section{Competing interests None declared.}

Patient consent for publication Not applicable.

Ethics approval Experimental procedures were approved by the University Committee on Laboratory Animals following the guidelines of the Canadian Council on Animal Care.

Provenance and peer review Not commissioned; externally peer reviewed.

Data availability statement Data are available on reasonable request. Inquiries about data and material should be made to BJ at the contact information listed previously.

Supplemental material This content has been supplied by the author(s). It has not been vetted by BMJ Publishing Group Limited (BMJ) and may not have been peer-reviewed. Any opinions or recommendations discussed are solely those of the author(s) and are not endorsed by BMJ. BMJ disclaims all liability and responsibility arising from any reliance placed on the content. Where the content includes any translated material, BMJ does not warrant the accuracy and reliability of the translations (including but not limited to local regulations, clinical guidelines, terminology, drug names and drug dosages), and is not responsible for any error and/or omissions arising from translation and adaptation or otherwise.

Open access This is an open access article distributed in accordance with the Creative Commons Attribution Non Commercial (CC BY-NC 4.0) license, which permits others to distribute, remix, adapt, build upon this work non-commercially, and license their derivative works on different terms, provided the original work is properly cited, appropriate credit is given, any changes made indicated, and the use is non-commercial. See http://creativecommons.org/licenses/by-nc/4.0/.

\section{ORCID iDs}

Adam Nelson http://orcid.org/0000-0002-3074-2713

Brent Johnston http://orcid.org/0000-0001-5456-2824

\section{REFERENCES}

1 Howlader N, Noone AM, Krapcho M, et al. SEER cancer statistics review, 1975-2016. Bethesda, MD: Natl Cancer Institute, 2019. https://seer.cancer.gov/csr/1975_2016/

2 Ireland L, Santos A, Ahmed MS, et al. Chemoresistance in pancreatic cancer is driven by stroma-derived insulin-like growth factors. Cancer Res 2016;76:6851-63.

3 Ren B, Cui M, Yang G, et al. Tumor microenvironment participates in metastasis of pancreatic cancer. Mol Cancer 2018;17:108.
4 Zhang L, Sanagapalli S, Stoita A. Challenges in diagnosis of pancreatic cancer. World J Gastroenterol 2018;24:2047-60.

5 Robert C. A decade of immune-checkpoint inhibitors in cancer therapy. Nat Commun 2020;11:3801.

6 Ali Al, Oliver AJ, Samiei T, et al. Genetic redirection of T cells for the treatment of pancreatic cancer. Front Oncol 2019;9:56.

7 Laheru D, Lutz E, Burke J, et al. Allogeneic granulocyte macrophage colony-stimulating factor-secreting tumor immunotherapy alone or in sequence with cyclophosphamide for metastatic pancreatic cancer: a pilot study of safety, feasibility, and immune activation. Clin Cancer Res 2008;14:1455-63.

8 Smyth MJ, Thia KY, Street SE, et al. Differential tumor surveillance by natural killer (NK) and NKT cells. J Exp Med 2000;191:661-8.

9 Swann JB, Uldrich AP, van Dommelen S, et al. Type I natural killer T cells suppress tumors caused by p53 loss in mice. Blood 2009;113:6382-5.

10 Kawano T, Cui J, Koezuka Y, et al. CD1d-restricted and TCRmediated activation of $\mathrm{V} \alpha 14$ NKT cells by glycosylceramides. Science 1997;278:1626-9.

11 Coquet JM, Chakravarti S, Kyparissoudis K, et al. Diverse cytokine production by NKT cell subsets and identification of an IL-17producing CD4-NK1.1- NKT cell population. Proc Natl Acad Sci U S A 2008;105:11287-92.

12 Gebremeskel S, Clattenburg DR, Slauenwhite D, et al. Natural killer T cell activation overcomes immunosuppression to enhance clearance of postsurgical breast cancer metastasis in mice. Oncoimmunology 2015;4:e995562.

13 Motohashi S, Nagato K, Kunii N, et al. A phase I-II study of $\alpha$-galactosylceramide-pulsed IL-2/GM-CSF-cultured peripheral blood mononuclear cells in patients with advanced and recurrent non-small cell lung cancer. J Immunol 2009;182:2492-501.

14 Metelitsa LS, Wu H-W, Wang $\mathrm{H}$, et al. Natural killer T cells infiltrate neuroblastomas expressing the chemokine CCL2. J Exp Med 2004;199:1213-21

15 Tachibana T, Onodera H, Tsuruyama T, et al. Increased intratumor V $\alpha 24$-positive natural killer T cells: a prognostic factor for primary colorectal carcinomas. Clin Cancer Res 2005;11:7322-7.

16 Tang R, Liu X, Liang C, et al. Deciphering the prognostic implications of the components and signatures in the immune microenvironment of pancreatic ductal adenocarcinoma. Front Immunol 2021;12:575.

17 Janakiram NB, Mohammed A, Bryant T, et al. Loss of natural killer T cells promotes pancreatic cancer in LSL-Kras ${ }^{\mathrm{G} 12 \mathrm{D} /+}$ mice. Immunology 2017;152:36-51.

18 Nagaraj S, Ziske C, Strehl J, et al. Dendritic cells pulsed with alphagalactosylceramide induce anti-tumor immunity against pancreatic cancer in vivo. Int Immunol 2006;18:1279-83.

19 Stojdl DF, Lichty BD, tenOever BR, et al. VSV strains with defects in their ability to shutdown innate immunity are potent systemic anticancer agents. Cancer Cell 2003;4:263-75.

20 Gebremeskel S, Nelson A, Walker B, et al. Natural killer T cell immunotherapy combined with oncolytic vesicular stomatitis virus or reovirus treatments differentially increases survival in mouse models of ovarian and breast cancer metastasis. J Immunother Cancer 2021;9:e002096.

21 Lichty BD, Breitbach CJ, Stojdl DF, et al. Going viral with cancer immunotherapy. Nat Rev Cancer 2014;14:559-67.

22 Shen W, Patnaik MM, Ruiz A, et al. Immunovirotherapy with vesicular stomatitis virus and PD-L1 blockade enhances therapeutic outcome in murine acute myeloid leukemia. Blood 2016;127:1449-58.

23 Vacchelli E, Eggermont A, Sautès-Fridman C, et al. Trial watch: oncolytic viruses for cancer therapy. Oncoimmunology 2013;2:e24612.

24 Lawson ND, Stillman EA, Whitt MA, et al. Recombinant vesicular stomatitis viruses from DNA. Proc Natl Acad Sci U S A 1995;92:4477-81.

25 Hong E, Usiskin IM, Bergamaschi C, et al. Configuration-dependent presentation of multivalent IL-15:IL-15R $\alpha$ enhances the antigenspecific $\mathrm{T}$ cell response and anti-tumor immunity. J Biol Chem 2016;291:8931-50.

26 Liu D, Song L, Wei J, et al. IL-15 protects NKT cells from inhibition by tumor-associated macrophages and enhances antimetastatic activity. J Clin Invest 2012;122:2221-33.

27 Stephenson KB, Barra NG, Davies E, et al. Expressing human interleukin-15 from oncolytic vesicular stomatitis virus improves survival in a murine metastatic colon adenocarcinoma model through the enhancement of anti-tumor immunity. Cancer Gene Ther 2012;19:238-46.

28 Xu X, Huang W, Heczey A, et al. NKT cells coexpressing a GD2specific chimeric antigen receptor and IL15 show enhanced in vivo persistence and antitumor activity against neuroblastoma. Clin Cancer Res 2019;25:7126-38. 
29 Heczey A, Courtney AN, Montalbano A, et al. Anti-GD2 CAR-NKT cells in patients with relapsed or refractory neuroblastoma: an interim analysis. Nat Med 2020;26:1686-90.

30 Topalian SL, Drake CG, Pardoll DM. Immune checkpoint blockade: a common denominator approach to cancer therapy. Cancer Cell 2015;27:450-61.

31 Mimura K, Teh JL, Okayama H, et al. PD-L1 expression is mainly regulated by interferon gamma associated with JAK-STAT pathway in gastric cancer. Cancer Sci 2018;109:43-53.

32 Melaiu O, Lucarini V, Giovannoni R, et al. News on immune checkpoint inhibitors as immunotherapy strategies in adult and pediatric solid tumors. Semin Cancer Biol 2022;79:18-43. doi:10.1016/j.semcancer.2020.07.001

33 Le Saux O, Lounici Y, Wajda P, et al. Neoadjuvant immune checkpoint inhibitors in cancer, current state of the art. Crit Rev Oncol Hematol 2021;157:103172.

34 Durgan K, Ali M, Warner P, et al. Targeting NKT cells and PD-L1 pathway results in augmented anti-tumor responses in a melanoma model. Cancer Immunol Immunother 2011;60:547-58.

35 Chandra S, Zhao M, Budelsky A, et al. A new mouse strain for the analysis of invariant NKT cell function. Nat Immunol 2015;16:799-800.

36 Partecke LI, Sendler M, Kaeding A, et al. A syngeneic orthotopic murine model of pancreatic adenocarcinoma in the C57/BL6 mouse using the Panc02 and 6606PDA cell lines. Eur Surg Res 2011;47:98-107.

37 Blank C, Brown I, Peterson AC, et al. PD-L1/B7H-1 inhibits the effector phase of tumor rejection by $\mathrm{T}$ cell receptor (TCR) transgenic CD8+ T cells. Cancer Res 2004:64:1140-5.

38 Porembka MR, Mitchem JB, Belt BA, et al. Pancreatic adenocarcinoma induces bone marrow mobilization of myeloidderived suppressor cells which promote primary tumor growth. Cancer Immunol Immunother 2012;61:1373-85.
39 Conroy T, Desseigne F, Ychou M, et al. Folfirinox versus gemcitabine for metastatic pancreatic cancer. N Engl J Med 2011;364:1817-25.

40 Feng M, Xiong G, Cao Z, et al. PD-1/PD-L1 and immunotherapy for pancreatic cancer. Cancer Lett 2017;407:57-65.

41 Heinhuis KM, Ros W, Kok M, et al. Enhancing antitumor response by combining immune checkpoint inhibitors with chemotherapy in solid tumors. Ann Oncol 2019;30:219-35.

42 Bae E-A, Seo H, Kim B-S, et al. Activation of NKT cells in an anti-PD-1-resistant tumor model enhances antitumor immunity by Reinvigorating exhausted CD8 T cells. Cancer Res 2018;78:5315-26.

43 Macho-Fernandez E, Cruz LJ, Ghinnagow R, et al. Targeted delivery of $\alpha$-galactosylceramide to $\mathrm{CD} 8 \alpha+$ dendritic cells optimizes type I NKT cell-based antitumor responses. J Immunol 2014;193:961-9.

44 Karakhanova S, Link J, Heinrich M, et al. Characterization of myeloid leukocytes and soluble mediators in pancreatic cancer: importance of myeloid-derived suppressor cells. Oncoimmunology 2015;4:e998519.

45 De Santo C, Salio M, Masri SH, et al. Invariant NKT cells reduce the immunosuppressive activity of influenza $A$ virus-induced myeloid-derived suppressor cells in mice and humans. J Clin Invest 2008;118:4036-48.

46 Russell SJ, Peng K-W, Bell JC. Oncolytic virotherapy. Nat Biotechnol 2012;30:658-70.

47 Nair S, Dhodapkar MV. Natural killer T cells in cancer immunotherapy. Front Immunol 2017;8:1178.

48 Spiers L, Coupe N, Payne M. Toxicities associated with checkpoint inhibitors-an overview. Rheumatology 2019;58:vii7-16.

49 Topalian SL, Hodi FS, Brahmer JR, et al. Safety, activity, and immune correlates of anti-PD-1 antibody in cancer. N Engl J Med 2012;366:2443-54.

50 Kern SE, Shi C, Hruban RH. The complexity of pancreatic ductal cancers and multidimensional strategies for therapeutic targeting. $J$ Pathol 2011;223:296-307. 